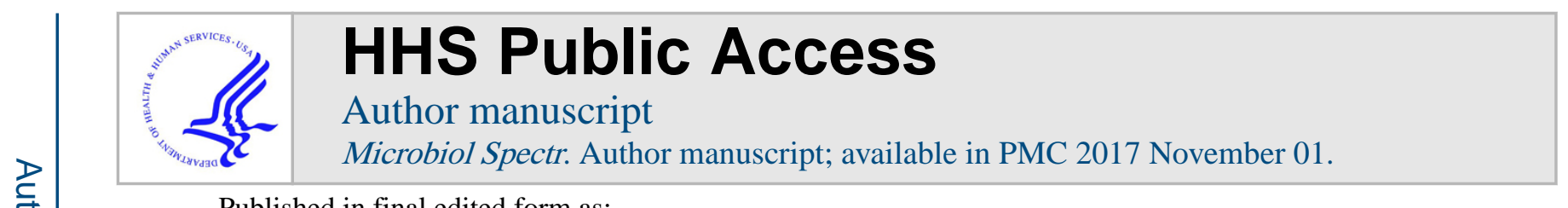

Published in final edited form as:

Microbiol Spectr. 2016 November ; 4(6): . doi:10.1128/microbiolspec.TNMI7-0001-2016.

\title{
Ocular Tuberculosis
}

\section{Daniel M. Albert and Meisha L. Raven ${ }^{1}$}

${ }^{1}$ Department of Ophthalmology and Visual Sciences, University of Wisconsin School of Medicine and Public Health, Madison, WI 53792

\begin{abstract}
Ocular tuberculosis is an extrapulmonary mycobacterial infection with variable manifestations. The reported incidence of ocular involvement varies considerably, depending on the criteria used for diagnosis and the population sampled. However, tuberculosis is thought to affect the lungs in $80 \%$ of patients, with the remaining $20 \%$ being affected in other organs, such as the eye. It is imperative for physicians to consider this diagnosis in their differential, as ocular tuberculosis can present in a fashion similar to that of more common conditions causing ocular inflammation. In addition, prompt recognition of the clinical signs and symptoms leads to quicker initiation of antituberculosis therapy.
\end{abstract}

\section{Historical Considerations}

Maitre-Jan (1) is often credited with publishing the earliest description of ocular tuberculosis (1707). Major contributions to the understanding of the disease mechanism were not made until the latter part of the 19th century. In 1855, Eduard von Jaeger first described the ophthalmoscopic appearance of choroidal tubercles (2). Cohnheim, in 1867 (3), showed that choroidal tubercles were similar microscopically to tubercles found elsewhere in the body and postulated that ocular involvement was a metastatic manifestation of systemic infection. In addition, Cohnheim was able to produce similar lesions in guinea pigs by injecting them with tuberculous material. In 1882, Koch identified the tubercle bacillus as the causative agent (4), and 1 year later, Julius von Michel identified the organism in the eye (5).

\section{Incidence}

The reported incidence of ocular involvement varies considerably, depending on the criteria used for diagnosis and the population sampled. Early medical writers considered the infection rare. However, the diagnosis was usually reserved for patients with obvious clinical tubercles. In 1890, Terson (6) reported two cases of tuberculous iritis in a population of 30,000 patients with ocular disease. In patients with known systemic tuberculosis, the incidence of ocular involvement is, as expected, much higher (7-9). A study reported in 1967 found an incidence of ocular tuberculosis of $1.4 \%$ in 10,524 patients at a tuberculosis sanitarium (7). In this group, 74 patients had uveal involvement; 54 had scleral or corneal involvement, including three cases of corneal ulcers; and 12 patients showed disseminated 
retinitis. Rarer manifestations were retinal periphlebitis (seven cases), phlyctenular conjunctivitis (six cases), and tuberculosis of the optic nerve (one case). This study illustrates the variety of ocular tissues that can be affected by tuberculosis.

In a more recent series, Rosen et al., in 1990, reported 12 patients with intraocular tuberculosis, 9 of whom presented with retinal vasculitis, 2 with choroidal tubercles, and 1 with chronic anterior uveitis (10). In a prospective study from Spain, Bouza et al. examined 100 randomly selected patients from a population of 300 patients with proven systemic tuberculosis (11). Ocular involvement was diagnosed in 18 patients (18\%). Choroidal involvement was present in all but one of these, and retinal involvement was found in 6 patients. Involvement of the anterior segment, sclera, and orbit were noted in single cases. There was an association between miliary tuberculosis and ocular involvement but no association between human immunodeficiency virus (HIV) positivity and ocular tuberculosis (11). Ocular involvement was associated with decreased visual acuity and other ocular symptoms.

A prospective study from Malawi, Africa, reported 3 patients with choroidal granulomas (2.8\%) among 109 patients presenting with fever and tuberculosis (12). In patients presenting with uveitis in north India, $9.86 \%$ of cases were felt to be caused by tuberculosis (13). In a prospective case series in Japan, $20.6 \%$ of 126 patients with uveitis had a positive tuberculosis skin test, and $7.9 \%$ were believed to have intraocular tuberculosis (14). In Saudi Arabia, tuberculosis was thought to be the cause in $17.8 \%$ of cases of uveitis seen at a university-based tertiary referral center (15). In patients presenting with uveitis in Boston between 1982 and 1992, tuberculosis caused this disease in $0.6 \%$ of cases (16). These studies reflect the wide variation in the reported incidence of ocular tuberculosis in differing populations and at various periods.

Recently, a retrospective study by Babu et al. examined 766 consecutive patients coinfected with the tuberculosis agent and HIV in southern India (17). Ocular tuberculosis was found in 15 patients (19 eyes [2.0\%]), the largest cohort in the reported literature. The most common presentation was choroidal tuberculoma (10 cases), followed by subretinal abscess ( 7 cases), panophthalmitis ( 1 case), and a conjunctival mass ( 1 case). Three of the seven cases of subretinal abscess progressed to panophthalmitis, a phenomenon rarely encountered in immunocompetent patients. While the previously cited work of Bouza et al. found no association between ocular tuberculosis and HIV/AIDS (11), these findings suggest that coinfection may lead to worse outcomes.

\section{Basic Mechanisms of Infection}

The eye can become infected with tuberculosis through several different mechanisms.

1. The most common form of ocular involvement is from hematogenous spread. The uveal tract (i.e., the iris, ciliary body, and choroid) is the coat of the eye most frequently involved, presumably because of its high vascular content. 
2. Primary exogenous infection of the eye, while unusual, can occur in the lids or in the conjunctiva. Other external tissues less commonly infected include the cornea, sclera, and lacrimal sac.

3. Secondary infection of the eye may occur by direct extension from surrounding tissues or by contamination with the patient's own sputum.

4.

Additionally, some forms of ocular tuberculosis, such as phlyctenular disease and Eales' disease, are thought to be the result of a hypersensitivity reaction. Attempts to establish an animal model for phlyctenular disease have led to various results (18-20).

Rich's law states that the extent of a tuberculous lesion is directly proportional to the number and virulence of the bacilli as well as the degree of hypersensitivity of the infected tissue (21). It is inversely proportional to the host's native and acquired resistance to the organism. Alan Woods was the first to utilize Rich's law to divide ocular tuberculosis into four distinct categories (22). Woods's four categories can be summarized as follows.

1. Foreign body-like reaction (e.g., miliary tubercles of the iris and choroid)

2. Acute circumscribed inflammation that may recur if the patient's resistance decreases (e.g., sclerokeratitis or Eales' disease)

3. Chronic inflammation with multiple recurrences (e.g., ciliary body tuberculoma)

4. Acute, rapidly spreading inflammation with necrosis, caseation, and occasionally a ruptured globe (tuberculous panophthalmitis)

\section{External Disease}

Tuberculosis can involve the lid, conjunctiva, cornea, and sclera. Tuberculous lid disease is rarely an isolated ocular finding, but it can manifest as an acute abscess (23) (a "cold abscess") or as a soft fluctuant mass without acute inflammation, a form that usually occurs in children (24). The skin of the lids may also display lupus vulgaris, the most common form of cutaneous tuberculosis, characterized by reddish-brown nodules that blanch to an "apple jelly" color when pressure is applied $(10,25)$. Primary infection of the conjunctiva has been reported (26-29), although it is unusual in developed countries. Patients usually present with ocular redness, discomfort, mucopurulent discharge, and lid edema. There is often an accompanying marked lymphadenitis (more common in the secondary form), which is absent in most other types of bacterial and allergic conjunctivitis and is less prominent in viral conjunctivitis. Typically, primary tuberculous conjunctivitis is a chronic disease that may lead to scarring of the involved tissue. The young are more susceptible to this form of tuberculosis than are the elderly. Diagnosis usually requires a high degree of clinical suspicion and positive identification of the organism with traditional acid-fast bacillus (AFB) stains or PCR on either a conjunctival smear or a biopsy sample (30, 31) (Fig. 1 to 4).

Corneal involvement can have the appearance of either phlyctenular keratoconjunctivitis or an interstitial keratitis. In phlyctenular keratoconjunctivitis, a small pink nodule is first noted at the limbus (32). The nodule generally migrates centrally, "dragging" superficial vessels 
along. Initially, the overlying epithelium is intact, but it often erodes, leading to an epithelial defect. The presentation includes photophobia, foreign-body sensation, redness, and tearing. The severity of symptoms usually corresponds to the degree of corneal involvement (Fig. 5). As previously noted, phlyctenular disease is believed to be a hypersensitivity reaction to a mycobacterial protein. Phlyctenulosis appears to be associated with a positive tuberculin skin test (TST) (33). It is, however, rare among patients with proven systemic tuberculosis (7). Attempts to reproduce phlyctenular disease in animal models have been made, with mixed success (18-20). In confirmed tuberculosis cases, treatment consists of systemic antituberculous chemotherapy in conjunction with topical steroids. Cycloplegia substantially relieves ocular discomfort, and topical antibiotics may be used as prophylaxis against secondary bacterial superinfection if epithelial defects are present.

"Interstitial keratitis" is a term used to describe inflammation and vascularization of the corneal stroma without endothelial or epithelial involvement. Tuberculous interstitial keratitis is characteristically unilateral and is seen clinically as a sectoral, peripheral stromal infiltrate with vascularization. Treatment consists of systemic as well as topical antituberculosis chemotherapy and cycloplegia. As in the case with phlyctenular keratoconjunctivitis, mycobacterial proteins are postulated as antigens that induce a corneal hypersensitivity reaction (34).

Tuberculous scleritis is usually seen anteriorly, as involvement of the posterior sclera is extremely rare. However, scleritis should be considered in patients who are unresponsive to the usual anti-inflammatory therapy for scleritis. Bloomfield and associates (35) reported a case of tuberculous scleritis in an 82-year-old female with extensive pulmonary tuberculosis. This type of scleritis usually presents as a localized area of dark red discoloration of the sclera with chronic granulomatous inflammation and caseous necrosis, possibly leading to scleromalacia. Nanda and coworkers (36) discussed a case of an 81-year-old male with culture-proven scleral tuberculosis. The patient initially presented with a scleral ulcer that worsened after initiation of oral prednisone (a medication often used for necrotizing scleritis). Examination of scrapings of the ulcer subsequently revealed numerous AFB. The patient responded rapidly to topical amikacin and the combination of oral rifampin and isoniazid (Fig. 6 and 7). Kesen and colleagues (37) reported a case of a 54-year-old female with multidrug-resistant tuberculosis, pulmonary involvement, and nodular scleritis. Cultures and AFB stains of tissue sections and bodily fluids, including bronchoalveolar lavage fluid, were negative. Despite treatment, scleral perforation ensued. Following enucleation, PCR of the sclera was positive for tuberculosis.

\section{Uveitis}

Until well into the 20th century, many cases of uveitis were attributed to presumed tuberculosis. It was gradually appreciated, however, that brucellosis, sarcoidosis, toxoplasmosis, and other infections can also cause uveitis with a similar clinical picture. Moreover, it was realized that uveitis in a tuberculosis patient may not be the direct result of an AFB infection. Accordingly, the apparent incidence of tuberculosis as the etiology of uveitis at the Wilmer Institute fell from 79\% in 1944 to 22\% in 1953 (22). The incidence of uveitis caused by tuberculosis at the Massachusetts Eye and Ear Infirmary from 1982 
through 1992 was reported to be $0.6 \%$ (16). In parts of the world where the prevalence of tuberculosis infection is higher in the general population, uveitis is still more likely to be attributed to tuberculosis. In patients presenting with uveitis in north India, $9.86 \%$ of cases were felt to be caused by tuberculosis (13). In a prospective case series in Japan, $20.6 \%$ of 126 patients with uveitis had a positive TST, and 7.9\% were felt to have intraocular tuberculosis (14). As previously noted, in Saudi Arabia, tuberculosis was stated to be the cause in $17.8 \%$ of uveitis cases seen in a major referral center (15).

Tuberculous anterior uveitis is classically a chronic granulomatous disease with an insidious onset. It is often accompanied by other ocular manifestations of chronic granulomatous inflammation, such as mutton-fat keratic precipitates (collections of inflammatory cells and macrophages) on the posterior aspect of the cornea. The iris may reveal Koeppe and Busacca nodules $(38,39)$. A nongranulomatous uveitis also occurs in tuberculosis, usually manifesting as small white keratic precipitates and an absence of iris nodules (40). In both granulomatous and nongranulomatous inflammation, there is inflammation of the anterior segment, and inflammatory cells and flare (the slit lamp manifestation of protein in the aqueous humor) can be seen in the anterior chamber. Uveitis can also manifest as simple iritis, the clinical signs of which are limited to cells and flare in the anterior chamber, or as iridocyclitis with involvement of the ciliary body. Iridocyclitis occurs clinically with inflammatory cells in the ciliary body and anterior vitreous and is associated with ciliary body pain and ciliary vasodilation. Alternatively, the inflammation may involve primarily the posterior part of the uvea (choroids). The various clinical presentations seen include choroidal tuberculoma, choroidal tubercles, multifocal choroiditis, and serpiginous-like choroiditis $(41,42)$.

\section{Choroiditis}

Choroidal tubercles are the most common form of ocular tuberculosis (41, 43, 44). Tubercles are usually multiple. In one of two reported cases of tuberculous choroiditis associated with AIDS, the posterior pole was riddled with "innumerable" tubercles (45), whereas in the second case, only two tubercles were seen (46). The tubercles may appear as white, gray, or yellow lesions with indistinct borders and may be accompanied by hemorrhages, exudates, or surrounding edema. Their size varies from about 0.5 to $3.0 \mathrm{~mm}$ in diameter, which may be estimated at the time of examination by comparing the extent of the lesions to the size of the optic disc, which is about $1.5 \mathrm{~mm}$ in diameter. Choroidal tubercles are usually found in the posterior pole and, when present, should be distinctly seen on careful examination with a direct ophthalmoscope (Fig. 8 and 9).

Paton (47) described the sudden appearance of choroidal tubercles in a patient 4 days after admission. The lesions were not observed on previous examinations, illustrating the potential need for repeated careful fundus examinations to demonstrate choroidal tubercles. In one series, only a single case of choroidal tubercles had been observed clinically in 63 autopsy cases with acute miliary tuberculosis (48). The authors suggested that this low incidence was the result of inadequate ophthalmoscopic examinations. Another study found a $60 \%$ incidence of choroidal tubercles (49). To permit an adequate examination, all pupils 
were dilated, the small children studied were sedated, and the average time devoted to each fundus examination in a child was $30 \mathrm{~min}$.

Choroidal tubercles should always be looked for on funduscopic examination when a patient is suspected to have tuberculosis or has a fever of unknown origin. The finding of choroidal tubercles is specific and allows the early institution of antituberculosis therapy even before the diagnosis is confirmed by positive sputum specimens. Although it has been claimed that choroidal tubercles occur only in terminally ill patients with miliary tuberculosis or tuberculous meningitis (47), the literature indicates that they can occur in a variety of clinical circumstances. Illingsworth and Wright (49) reported the occurrence of choroidal tubercles in very young children with acute miliary tuberculosis. A case was described in which miliary tubercles were associated with optic neuropathy but without other systemic lesions (50). Massaro and colleagues (51) emphasized that tubercles occasionally occur in patients with pulmonary tuberculosis without evidence of miliary tuberculosis. Mehta and associates found choroidal tubercles in $34.6 \%$ of 52 patients with neurotuberculosis, diagnosed by the presence of intracranial granulomas or tuberculous meningitis (52). About half of the patients with neurotuberculosis had systemic involvement. The odds ratio for the presence of systemic tuberculosis with choroidal tubercles was 5.6 to 1 , providing further evidence that choroidal tubercles may be one of the earliest signs of disseminated disease. There have been reports of other manifestations of tuberculous infection of the choroid, including multifocal choroiditis (53) and ser-piginous-like choroiditis (54).

Serpiginous-like choroiditis affects the choroid and choriocapillaris. Classically, it begins in the peripapillary region as either solitary or multifocal lesions. Solitary lesions are described as diffuse and plaque-like. Multi-focal lesions are discrete and initially noncontiguous. However, later in the disease process they progress to form diffuse lesions with an active edge which is often confused with serpiginous choroiditis (Fig 10) (55). Fluorescein angiography (FA) reveals initial hypofluorescence of the active edge of lesions that progresses to late hyperfluorescence (Fig. 11). Active lesions on indocyanine green angiography appear hypocyanescent throughout (39).

Several cases of tuberculous choroiditis in patients with AIDS and systemic tuberculosis have been reported $(56,57)$. The choroidal tubercles in three patients were discovered after the initiation of systemic antituberculous chemotherapy, when they were considered to be in a healing stage (57). One patient with central nervous system tuberculosis and tuberculous choroiditis improved dramatically after initiation of triple antituberculosis therapy. The cerebrospinal fluid findings returned to normal, and visual acuity improved from 20/200 to 20/20 (52).

It has been suggested that ocular tuberculosis may occur more often in immunocompromised patients. In a study of eyes from the autopsies of AIDS patients, however, intraocular tuberculosis was found in 2 eyes of 235 patients (58). Additionally, Babu and colleagues found ocular tuberculosis present in only $1.95 \%$ of patients with HIV/ AIDS (15 of 766 consecutive cases) (17). Although HIV is an important risk factor for having systemic tuberculosis, the likelihood of ocular involvement does not appear to be related to the HIV status of the patient (11). 
Before the advent of chemotherapy, the prognosis for patients with choroidal tubercles was uniformly poor. However, the prognosis is much improved with the rapid use of systemic antituberculosis agents. No specific local therapy is needed. Many of these lesions regress completely, with minimal residual damage $(51,59,60)$. Other lesions heal with focal chorioretinal scars. An exception to this rule may be tuberculous choroiditis in the setting of AIDS: the ocular changes have been reported to progress in spite of vigorous antituberculosis chemotherapy (46). Reports of acquired resistance of mycobacteria are increasing (61), and such resistance may be caused by several mechanisms. In the case reported by Snider and coworkers (61), "resistance" was thought to be the result of incomplete antibiotic treatment and occurred after 8 months of isoniazid and rifampin therapy.

\section{Choroidal Tuberculomas}

Whereas choroidal tubercles are generally small and multiple, tuberculomas are usually larger lesions (up to $7 \mathrm{~mm}$ in diameter) and solitary. They are typically better defined and have less surrounding edema than tubercles (Fig. 9 and 12 to 14). Tuberculomas have a predilection for the foveal and perifoveal area. Large tubercles have been confused with metastatic tumors, leading to unnecessary enucleation (62). Tuberculomas of the uveal tract tend to occur in young adults and have a chronic course with symptoms persisting over months to years (63). Affected patients often have a history of old, healed pulmonary tuberculosis, although sometimes the presumed diagnosis of choroidal tuberculosis may lead to the subsequent diagnosis and treatment of pulmonary tuberculosis (64).

FA in patients with choroidal tubercles shows hypofluorescent lesions during the early phase that become hyperfluorescent towards the late phase (Fig. 8C to F) (39). Normal or slightly dilated overlying retinal vessels, late leakage, and, in some cases, associated serous neurosensory retinal detachment can be seen (64-66). FA is useful in differentiating among choroidal hemangiomas, foreign bodies, metastatic tumors, and melanoma. FA cannot distinguish between tuberculosis and other granulomatous inflammations, such as sarcoid. Serial FA may also be useful to assess a patient's responses to therapy (66). Saxena et al. looked at FA and spectral domain optical coherence tomography (OCT) in an immunocompetent 18-year-old female with a choroidal tuberculoma. OCT revealed attachment between the retinal pigment epithelium (RPE)-choriocapillaris layer and neurosensory retina over the granuloma (Fig. 15A), which was previously reported in the literature (67). Salman et al. (68) coined this the "contact sign" and felt that this was due to inflammatory adhesions causing the neurosensory retina to stick to the RPE. However, granularity of the outer photoreceptor layer secondary to phagocytoses of the cells, and proliferating RPE cells (Fig. 15B) were novel findings. Ultrasound has also been found to be useful in the diagnosis of choroidal tuberculomas (11). The prognosis for resolution of the lesion is usually good with systemic treatment, but if the macular region is involved, visual loss may be permanent (69). 


\section{Ciliary Body Tuberculoma}

Ciliary body tuberculoma is a rare but aggressive form of uveal tuberculosis. It occurs most frequently before the fourth decade of life and tends to follow a chronic, smoldering course with intermittent recurrences. $\mathrm{Ni}$ and associates (63) reported three cases that were enucleated at the Shanghai First Hospital. Results of the purified protein derivative (PPD) test were positive for all three patients. Two patients presented with painless loss of vision and a 1-month to 5-year history of intraocular inflammation. All patients were in generally good health, and only one patient had signs of systemic tuberculosis on examination. There was evidence of granulomatous anterior uveitis in all three patients. On histopathological examination, the eyes showed inflammatory infiltrates of the iris consisting of plasma cells, monocytes, lymphocytes, and typical caseous granulomas in the ciliary body. The authors reported that the fellow eyes of two patients did well after the initiation of chemotherapy; the third patient was lost to follow-up.

\section{Tuberculous Retinitis}

Tuberculosis of the retina most commonly results from the direct extension from the underlying uvea but may also be caused by hematogenous spread. Retinal lesions may take the form of either focal tubercles or diffuse retinitis. The clinical features include vitreous opacification, gray-white retinal lesions (34), and, rarely, an isolated vasculitis (70) or retinal vascular tumor (71).

Neovascularization and peripheral capillary occlusion have been described in cases of choroiditis, chorioretinitis, and retinal vasculitis (Fig. 16 to 18) (10, 72, 73). A combination of systemic treatment and retinal photocoagulation has been advocated for treatment of retinal neovascularization related to tuberculosis $(10,73)$.

Mahyudin et al. (74) described a case of a central retinal vein occlusion in a 23-year-old male without any signs of systemic tuberculosis. Initially, only retinal hemorrhages, cotton wool spots, venous engorgement, and a swollen optic disc were seen. No iritis or vitritis was present. Two weeks later, fundus examination revealed fresh retinal hemorrhages, vessel sheathing, preretinal whitish opacities, 2+ anterior chamber cell, and 2+ vitritis. PCR analysis of vitreous fluid revealed Mycobacterium tuberculosis, and the patient was subsequently started on antituberculosis treatment.

Eales' disease, a poorly understood form of retinal perivasculitis, has sometimes been linked to tuberculosis $(22,75)$. The disease predominately affects the peripheral retina and is most common in young and otherwise healthy adults (76). Patients with Eales' disease often present with a sudden painless decrease in vision secondary to a vitreous hemorrhage. After the vitreous hemorrhage clears, perivascular exudates and hemorrhages are visible along the retinal vessels. The vasculitis can progress to venous thrombosis, neovascularization, glial tissue proliferation, and eventual tractional retinal detachment. There have been reports of patients with Eales' disease who have had PCR examination of vitreous fluid and epiretinal membrane tissue that was positive for Mycobacterium tuberculosis DNA, which supports the contention that tuberculosis is causative for Eales' disease $(76,77)$. Positive cultures of $M$. 
tuberculosis could not be successfully grown from any of these samples, suggesting that nonviable organisms in Eales' disease may incite a hypersensitivity reaction (78).

Verma et al. (79) extracted DNA from a paraffin-embedded eyeball for nested PCR analysis from a patient that was previously diagnosed with Eales' disease. Although Ziehl-Neelsen stain was negative for AFB, nested PCR was positive for the M. tuberculosis genome.

\section{Tuberculous Panophthalmitis}

Acute tuberculous panophthalmitis usually occurs in children or severely ill adults with evidence of systemic tuberculosis. The duration of ocular involvement and of symptoms is relatively short (1 to 2 months). Presentation includes painless, progressive visual loss, decreased ocular motility, corneal cloudiness, signs of granulomatous ocular inflammation, and low intraocular pressure. Perforation of the globe can occur, usually at a site near the equator. Predisposing factors for systemic spread to the eye include poor nutrition, chronic illness, and intravenous drug abuse $(63,64)$.

There have been reports of tuberculous panophthalmitis and endophthalmitis masquerading as ocular tumors $(80,81)$. A case of tuberculous panophthalmitis has been described in a woman with systemic lupus erythematosus. She initially presented with a serous retinal detachment that progressed to panophthalmitis with no light perception and glaucoma. Tuberculosis was diagnosed in a patient after enucleation, with recurring postoperative orbital abscesses which improved after administration of systemic antituberculous therapy (82).

\section{Orbital Tuberculosis}

Tuberculosis of the orbit is extremely rare in the United States and Europe. A review of the literature revealed only five cases reported in the Western literature over the past 50 years (83). Three cases were associated with pulmonary tuberculosis (84-86), one was associated with tuberculous sinusitis, and one was associated with tuberculous pericarditis (83). Four of the five cases presented with ocular symptoms which included pain and proptosis (83), lid swelling (85), and intermittent periorbital swelling associated with headache and epistaxis (86). In one case, proptosis was an incidental finding in a patient who presented with fatigue, dry cough, and fever (83). Among other clinical findings in the five cases were decreased vision and visual field abnormalities, chemosis, Marcus Gunn pupil, epiphora, increased orbital resistance to retropulsion, and an orbital mass visualized on computerized tomography. Diagnosis was confirmed in four cases by orbital tissue biopsy and culture. In four cases, the orbital masses were monitored with computed tomography and observed to resolve over the 3 months to 6 months following the initiation of systemic antituberculosis chemotherapy; one case was treated with additional surgery.

Moorfields Eye Hospital in London, England, identified nine patients in a 10-year period with a diagnosis of orbital or periocular tuberculosis. Of those patients, three had cutaneous involvement, two had tuberculous dacryocystitis, and four had diffuse orbital tuberculosis (88). 
A case of orbital tuberculosis in a 37-year-old American man (84) manifested with a recurring orbital abscess that was not responding to repeated drainage and broad-spectrum antibiotic therapy and steroids. Tuberculosis was diagnosed by histopathological examination of an orbital biopsy sample obtained 1 month after initial presentation.

In India, where tuberculosis is endemic, cases of orbital tuberculosis are more common. In one report, three cases of isolated presumed orbital tuberculoma in children were described. The patients presented with painful proptosis, low-grade fever, lid swelling, mechanical ptosis, and decreased vision. In all three cases, tuberculous mycobacteria were found in orbital specimens obtained by fine-needle aspiration. Symptoms improved with systemic antituberculosis therapy $(88,89)$. There have also been reports from Europe of a Somalian child with an orbital tuberculosis abscess and a woman presenting with dacryoadenitis secondary to tuberculosis $(90,91)$.

\section{Diagnosis}

Before the introduction of PCR technology, a definitive diagnosis of ocular tuberculosis was often elusive because it required the demonstration of the Mycobacterium tuberculosis bacilli in ocular tissues or secretions by microscopy or culture. Opportunities for culture and biopsy may arise in cases of eyelid, orbital, or corneal involvement. The majority of cases, however, show intraocular involvement wherein a biopsy is not practical. Aqueous and vitreous paracentesis has generally failed to yield positive bacterial cultures (22). In addition to the difficulty of isolating the organism, the extreme variability of ocular manifestations makes routine clinical diagnosis difficult. Finally, the similarity to the presentation of other granulomatous inflammations adds to the diagnostic challenge. As a result, the vast majority of cases with a clinical diagnosis of ocular tuberculosis but without a definitive laboratory diagnosis should more correctly be labeled "presumed ocular tuberculosis."

Woods (22) outlines a thorough diagnostic approach to suspected ocular tuberculosis. A complete history (including exposures and systemic symptoms), physical examination, sputum smear and culture, PPD test, and chest radiography should be performed. Sixty percent of patients with extrapulmonary tuberculosis have no evidence of pulmonary disease, and chest X-rays are normal in cases of latent tuberculosis. Therefore, the absence of clinically noticeable pulmonary tuberculosis does not rule out the possibility of ocular involvement $(92,93)$. Other possible causes of granulomatous inflammation, such as syphilis, brucellosis, toxoplasmosis, Toxocara infection, and sarcoid, must be ruled out by history, examination, and appropriate serologic testing.

As alluded to earlier, an initial workup that yields negative results should not eliminate tuberculosis from the differential diagnosis. Abrams and Schlaegel found that 17 of 18 cases of tuberculous uveitis showed no active or inactive evidence of tuberculosis on chest radiography. They caution against requiring a strongly positive PPD response to make the diagnosis of ocular tuberculosis (94). The PPD is less likely to be reactive in immunosuppressed patients. These authors report that of 18 patients with presumed tuberculous uveitis (based on history, physical examination, tests to rule out other etiologies, TST, and the isoniazid therapeutic test) who were tested with intermediate-strength (5 
tuberculin units) PPD, only nine experienced at least $5 \mathrm{~mm}$ of induration, five experienced no reactivity at all, and four had erythema only. The five with no reaction to the intermediate PPD were retested with the second-strength PPD (250 tuberculin units). Only two patients experienced a reaction of more than $5 \mathrm{~mm}$. All of the reported cases improved clinically with an isoniazid therapeutic test ( 3 weeks of $300 \mathrm{mg}$ of isoniazid per day) and remained inflammation free, without relapse, during 1 year of antituberculosis treatment. An isoniazid therapeutic trial was recommended for patients with uveitis in whom tuberculosis was the suspected etiology on the basis of either history or a positive reaction to an intermediatestrength PPD test. An isoniazid test result is considered positive if there is "dramatic improvement" in 1 to 3 weeks of therapy. This trial, however, may be falsely negative for patients with AIDS or in cases of drug-resistant disease.

With the development of diagnostic molecular biology techniques, diagnosis based on detection of mycobacterial DNA via PCR has become the method of choice. There have also been reports of testing for tuberculosis antigens, such as the cord factor antigen, via enzymelinked immunosorbent assay (95). PCR yields results much faster than mycobacterial cultures, which can require several weeks for a positive result. Detection of mycobacterial DNA has been successful with a variety of nonocular tissues (96). In the past decade, there have been several reports of PCR being used to detect tuberculosis in a host of ocular tissues, including eyelid skin, conjunctiva, aqueous and vitreous humors, fixed choroidal tissue, subretinal fluid, and epiretinal membranes (37, 76, 77, 97-102). In one recent case from the Illinois Eye and Ear Infirmary, the diagnosis of ocular tuberculosis was made by PCR following negative cultures and AFB stains of bodily fluids and tissues (37). Additionally, a case-control study of 22 patients with known tuberculosis uveitis demonstrated a $77.2 \%$ sensitivity and $92.1 \%$ specificity $(P=0.022)$ for nested PCR in the detection of Mycobacterium tuberculosis in aqueous and vitreous aspirates (103). While further investigations are still needed to determine the sensitivity and specificity of PCR and enzyme-linked immunosorbent assay for tuberculosis in ocular tissues, these techniques have added valuable alternatives for the diagnosis of intraocular tuberculosis infection.

Interferon gamma release assays (IGRA) are blood-based diagnostic tests that detect the presence of both active and latent mycobacterial infections in the body. IGRA has demonstrated a sensitivity comparable or superior to that of the TST in the immunocompetent, a more robust response than TST in the immunocompromised (those infected with HIV, those on immunosuppressive drug therapy, the elderly, and those on dialysis), and potential as a possible marker of treatment response (104). In a retrospective cohort study, Ang and associates (105) found that IGRA was more specific but less sensitive than TST in the diagnosis of tuberculous uveitis. These findings suggest that the two tests should still be interpreted together.

\section{Treatment}

Once the diagnosis of ocular tuberculosis is made, systemic antituberculosis therapy should be initiated immediately. Systemic treatment is successful in the vast majority of cases, with subsequent resolution of symptoms, inflammation, and often an improvement in visual acuity to near premorbid levels. However, cases are reported in which traditional therapies 
fail to resolve the ocular infection. In one case, a choroidal tuberculoma did not respond to chemotherapy, and the eye eventually became blind and painful, necessitating enucleation (66). Blodi and colleagues (45) reported that choroidal tuberculosis rapidly progressed despite treatment in an HIV-positive patient. The increasing prevalence of acquired drug resistance of mycobacteria in response to incomplete chemotherapy should also be kept in mind with patients not responding to conventional antituberculous therapy.

Any patient with a clinical picture highly suspicious for ocular tuberculosis should be treated with a multi-drug regimen of proven efficacy. Because pulmonary infection and other foci of infection may coexist, primary treatment should always be systemic. Ocular penetration of these drugs varies, and additional topical treatment may be useful in patients with external disease.

Topical ointment and subconjunctival injection of isoniazid can lead to adequate intraocular drug levels, especially in the anterior segment. Parenteral administration, however, causes higher vitreous drug levels that make this route of administration the method of choice in posterior intraocular tuberculosis (106).

Topically administered streptomycin is absorbed by the corneal stroma and penetrates the aqueous at high levels, but only in the presence of an epithelial defect. Parenteral administration of high doses can lead to detectable levels in all ocular tissues (107). Intravitreal injection is more successful in generating therapeutic intraocular levels, but high doses may lead to retinal damage (108).

Rifampin administered orally attained an aqueous concentration of 2 to $9 \%$ of its level in serum, which may be a therapeutic level against some organisms (109). Studies regarding the ocular penetration of pyrazinamide have not yet been published.

It should be noted that ethambutol, one of the staples of antituberculosis pharmacotherapy, has significant ocular toxicity (110). Toxicity is dose related and rarely seen with a daily dose under $15 \mathrm{mg} / \mathrm{kg}$ of body weight. One to two percent of patients on a daily dose of 25 $\mathrm{mg} / \mathrm{kg}$ or more experience significant ocular effects, most commonly optic neuritis. This toxicity can occur in axial and periaxial forms. Axial optical neuritis is associated with macular degeneration that manifests with decreased central visual acuity and decreased green color perception. Periaxial optic neuritis leads to paracentral scotomas (visual field defects) with normal visual acuity and color perception. Other side effects include photophobia, extraocular muscle paresis, and toxic amblyopia. Symptoms of optic neuritis are most often abrupt and begin 3 to 6 months after the onset of ethambutol therapy.

All patients to be started on ethambutol should undergo a baseline ophthalmic examination including visual acuity, color vision, and visual fields (110). Patients should be examined every 2 to 4 weeks when dosages greater than $15 \mathrm{mg} / \mathrm{kg} / \mathrm{day}$ are used and every 3 to 6 months for lower doses. The patient should be given a vision card and instructed to stop the ethambutol and seek an ophthalmic examination immediately if there is a decrease in visual acuity. Most symptoms resolve over a period of 3 to 12 months, but cases with permanent vision loss have been reported. If the vision does not improve after 10 to 15 weeks of drug 
discontinuation, treatment with parenteral hydroxocobalamin, $40 \mathrm{mg}$ daily over a 10 - to 28 week period, should be considered.

There has been a growing interest in developing new therapies for tuberculosis due to the increasing incidence of multidrug resistance. Fourth-generation fluoroquinolones like moxifloxacin and gatifloxacin are currently being studied and show promising results (111, 112). However, more prospective randomized trials need to be done before recommending definitive treatment guidelines.

The role of laser therapy in the treatment of ocular tuberculosis has yet to be defined. Balashevich (113) has used argon laser photocoagulation on tuberculous chorioretinitis lesions near the fovea and concluded that such treatment results in better visual acuity than conventional treatment does. Jabbour and associates (64) reported, however, that a subretinal granuloma-like lesion had grown outside previously placed photocoagulation scars. Gur and colleagues (73) and Rosen and coworkers (10) reported on the successful use of sector photocoagulation for the treatment of subretinal neovascularization in a case of chorioretinitis. Laser therapy should never be used as primary treatment without systemic antituberculosis chemotherapy. Furthermore, treatment should be delayed until the diagnosis is established and the response to chemotherapy is confirmed in order to avoid further confusion of the clinical picture and course.

Recently, a new potential target for treatment has been identified. From studies of Mycobacterium marinum in zebrafish, Volkman and associates have identified early secreted antigenic target 6 (ESAT-6), a protein secreted by mycobacteria that induces production of matrix metalloproteinase 9 (MMP9) in epithelial cells (114). MMP9 acts as a trophic factor for macrophages. As the original infected macrophage dies, phagocytosis by the newly recruited macrophages leads to their subsequent infection, resulting in exponential bacterial growth and granuloma proliferation. Interruption of MMP9 function resulted in attenuated bacterial growth and granuloma formation in the animal model and shows promise as a novel antituberculosis treatment strategy for humans.

\section{Acknowledgments}

We gratefully acknowledge the contributions of Robert J. Peralta, Matthew J. Thompson, Pascal D. Imesch, and Ellen J. Dehm in previous editions of this chapter.

\section{References}

1. Maitre-Jan, A. Traite des maladies de l'oeil et des remedes propres pour leur guerison Enrichy de plusieurs experiences de physique. Jacquesle Febvre Troyes; France: 1707.

2. von Jaeger E. Über choroidealtuberkel. Desterr Ztschr Pract Heilke. 1855; 1855:9-10.

3. Cohnheim J. Ueber tuberkulose der choroiden. Virchows Arch A Pathol Anat Histopathol. 1867; 39:49-69.

4. Koch R. Die Aetiologe der Tuberculose. Berliner Klin Wochenschr. 1882; 1882:221-230.

5. von Michel J. Über iris und iritis. Albrecht Von Graefes Arch Klin Exp Ophthalmol. 1881; 27:171282.

6. Terson A. Tuberculose oculaire: excision d'un tubercule de l'iris suivi de succes. Arch Ophthalmol. 1890; 1890:7-14. 
7. Donahue HC. Ophthalmologic experience in a tuberculosis sanatorium. Am J Ophthalmol. 1967; 64:742-748. [PubMed: 6061532]

8. Glover LP. Some eye observations in tuberculosis patients at the State Sanatorium, Cresson, Pennsylvania. Am J Ophthalmol. 1930; 13:411-412.

9. Goldenberg M, Fabricant N. The eye in the tuberculous patient. Trans Sect Ophthalmol Am Med Assoc. 1909; 1909:135.

10. Rosen PH, Spalton DJ, Graham EM. Intraocular tuberculosis. Eye (London). 1990; 4:486-492.

11. Bouza E, Merino P, Muñoz P, Sanchez-Carrillo C, Yáñez J, Cortés C. Ocular tuberculosis. A prospective study in a general hospital. Medicine (Baltimore). 1997; 76:53-61. [PubMed: 9064488]

12. Beare NA, Kublin JG, Lewis DK, Schijffelen MJ, Peters RP, Joaki G, Kumwenda J, Zijlstra EE. Ocular disease in patients with tuberculosis and HIV presenting with fever in Africa. Br J Ophthalmol. 2002; 86:1076-1079. [PubMed: 12234881]

13. Singh R, Gupta V, Gupta A. Pattern of uveitis in a referral eye clinic in north India. Indian J Ophthalmol. 2004; 52:121-125. [PubMed: 15283216]

14. Morimura Y, Okada AA, Kawahara S, Miyamoto Y, Kawai S, Hirakata A, Hida T. Tuberculin skin testing in uveitis patients and treatment of presumed intraocular tuberculosis in Japan. Ophthalmology. 2002; 109:851-857. [PubMed: 11986087]

15. Al Dhahri H, Al Rubaie K, Hemachandran S, Mousa A, Gikandi PW, Al-Mezaine HS, Abu ElAsrar AM. Patterns of uveitis in a university-based tertiary referral center in Riyadh, Saudi Arabia. Ocul Immunol Inflamm. Jul 24.2014 doi: 10.3109/09273948.2014.939197

16. Rodriguez A, Calonge M, Pedroza-Seres M, Akova YA, Messmer EM, D'Amico DJ, Foster CS. Referral patterns of uveitis in a tertiary eye care center. Arch Ophthalmol. 1996; 114:593-599. [PubMed: 8619771]

17. Babu RB, Sudharshan S, Kumarasamy N, Therese L, Biswas J. Ocular tuberculosis in acquired immunodeficiency syndrome. Am J Ophthalmol. 2006; 142:413-418. [PubMed: 16935585]

18. Gibson WS. The etiology of phlyctenular conjunctivitis. Am J Dis Child. 1918; 15:81-115.

19. Rosenhauch E. Ueber das Verhaeltnis phlyctaenularer Augenentzuendungen zu Tuberkulose. Albert von Graefes Arch Ophthalmol. 1910; 1910:370-396.

20. Thygeson P, Diaz-Bonnet V, Okumoto M. Phlyctenulosis. Attempts to produce an experimental model with BCG. Invest Ophthalmol. 1962; 1:262-266. [PubMed: 13921137]

21. Rich A, McCordock H. An enquiry concerning the role of allergy, immunity and other factors of importance in the pathogenesis of human tuberculosis. Bull Johns Hopkins Hosp. 1929; 44:273.

22. Woods, AC. Endogenous Uveitis. Williams \& Wilkins; Baltimore, MD: 1961.

23. Zorić LD, Zorić DL, Zorić DM. Bilateral tuberculous abscesses on the face (eyelids) of a child. Am J Ophthalmol. 1996; 121:717-718. [PubMed: 8644820]

24. Mehta DK, Sahnikamal, Ashok P. Bilateral tubercular lid abscess-a case report. Indian J Ophthalmol. 1989; 37:98. [PubMed: 2583794]

25. Domonkos, AN.; Arnold, HL.; Odom, RB. Andrew's Diseases of the Skin, Clinical Dermatology. 7th. WB Saunders; Philadelphia, PA: 1982.

26. Chandler AC Jr, Locatcher-Khorazo D. Primary tuberculosis of the conjunctiva. Arch Ophthalmol. 1964; 71:202-205. [PubMed: 14089390]

27. Fernandes M, Vemuganti GK, Pasricha G, Bansal AK, Sangwan VS. Unilateral tuberculous conjunctivitis with tarsal necrosis. Arch Ophthalmol. 2003; 121:1475-1478. [PubMed: 14557188]

28. Zaborowski AG, Gundry BN, Masenya ME, Visser L. Primary tuberculous keratoconjunctivitis. Eye (London). 2006; 20:978-979.

29. Rose JS, Arthur A, Raju R, Thomas M. Primary conjunctival tuberculosis in a 14 year old girl. Indian J Tuberc. 2011; 58:32-34. [PubMed: 21434554]

30. Cook CD, Hainsworth M. Tuberculosis of the conjunctiva occurring in association with a neighbouring lupus vulgaris lesion. Br J Ophthalmol. 1990; 74:315-316. [PubMed: 2354142]

31. Jennings A, Bilous M, Asimakis P, Maloof AJ. Mycobacterium tuberculosis presenting as chronic red eye. Cornea. 2006; 25:1118-1120. [PubMed: 17133069] 
32. Goyal JL, Jain P, Arora R, Dokania P. Ocular manifestations of tuberculosis. Indian J Tuberc. 2015; 62:66-73. [PubMed: 26117474]

33. Philip RN, Comstock GW, Shelton JH. Phlyctenular keratoconjunctivitis among Eskimos in Southwestern Alaska. I. Epidemiologic characteristics. Am Rev Respir Dis. 1965; 91:171-187. [PubMed: 14253167]

34. Spencer, WH. Ophthalmic Pathology: An Atlas and Textbook. Vol. 1. WB Saunders; Philadelphia, PA: 1996.

35. Bloomfield SE, Mondino B, Gray GF. Scleral tuberculosis. Arch Ophthalmol. 1976; 94:954-956. [PubMed: 938286]

36. Nanda M, Pflugfelder SC, Holland S. Mycobacterium tuberculosis scleritis. Am J Ophthalmol. 1989; 108:736-737. [PubMed: 2512813]

37. Kesen MR, Edward DP, Rao NA, Sugar J, Tessler HH, Goldstein DA. Atypical infectious nodular scleritis. Arch Ophthalmol. 2009; 127:1079-1080. [PubMed: 19667360]

38. Tabbara KF. Ocular tuberculosis: anterior segment. Int Ophthalmol Clin. 2005; 45:57-69. [PubMed: 15791158]

39. Gupta, A.; Bansal, R.; Gupta, V. Tuberculosis, leprosy, and brucellosis. In: Yanoff, M.; Duker, JS., editors. Ophthalmology. Elsevier; 2014. p. 716-719.

40. Abrams J, Schlaegel TF Jr. The role of the isoniazid therapeutic test in tuberculous uveitis. Am J Ophthalmol. 1982; 94:511-515. [PubMed: 6890314]

41. Helm CJ, Holland GN. Ocular tuberculosis. Surv Ophthalmol. 1993; 38:229-256. [PubMed: 8310395]

42. Zhang M, Zhang J, Liu Y. Clinical presentations and therapeutic effect of presumed choroidal tuberculosis. Retina. 2012; 32:805-813. [PubMed: 21878856]

43. Heiden D, Saranchuk P, Keenan JD, Ford N, Lowinger A, Yen M, McCune J, Rao NA. Eye examination for early diagnosis of disseminated tuberculosis in patients with AIDS. Lancet Infect Dis. 2016; 16:493-499. [PubMed: 26907735]

44. Siedner MJ, Ng CK, Bassett IV, Katz IT, Bangsberg DR, Tsai AC. Trends in CD4 count at presentation to care and treatment initiation in sub-Saharan Africa, 2002-2013: a meta-analysis. Clin Infect Dis. 2015; 60:1120-1127. [PubMed: 25516189]

45. Blodi BA, Johnson MW, McLeish WM, Gass JD. Presumed choroidal tuberculosis in a human immunodeficiency virus infected host. Am J Ophthalmol. 1989; 108:605-607. [PubMed: 2510520]

46. Croxatto JO, Mestre C, Puente S, Gonzalez G. Nonreactive tuberculosis in a patient with acquired immune deficiency syndrome. Am J Ophthalmol. 1986; 102:659-660. [PubMed: 3777088]

47. Paton RT. The clinical significance of choroidal tubercles. Ann Intern Med. 1932; 5:997-999.

48. Chapman CB, Whorton CM. Acute generalized miliary tuberculosis in adults. N Engl J Med. 1946; 235:239-248. [PubMed: 20996257]

49. Illingworth RS, Wright T. Tubercles of the choroid. BMJ. 1948; 2:365-368. [PubMed: 18877342]

50. Mansour AM, Haymond R. Choroidal tuberculomas without evidence of extraocular tuberculosis. Graefes Arch Clin Exp Ophthalmol. 1990; 228:382-383. [PubMed: 2401424]

51. Massaro D, Katz S, Sachs M. Choroidal tubercles. A clue to hematogenous tuberculosis. Ann Intern Med. 1964; 60:231-241. [PubMed: 14114443]

52. Mehta S, Chauhan V, Hastak S, Jiandani P, Dalal P. Choroidal tubercles in neurotuberculosis: prevalence and significance. Ocul Immunol Inflamm. 2006; 14:341-345. [PubMed: 17162604]

53. Grewal A, Kim RY, Cunningham ET Jr. Miliary tuberculosis. Arch Ophthalmol. 1998; 116:953954. [PubMed: 9682716]

54. Gupta V, Gupta A, Arora S, Bambery P, Dogra MR, Agarwal A. Presumed tubercular serpiginouslike choroiditis: clinical presentations and management. Ophthalmology. 2003; 110:1744-1749. [PubMed: 13129872]

55. Bansal R, Gupta A, Gupta V, Dogra MR, Sharma A, Bambery P. Tubercular serpiginous-like choroiditis presenting as multifocal serpiginoid choroiditis. Ophthalmology. 2012; 119:23342342. [PubMed: 22892153] 
56. Muccioli C, Belfort R Jr. Presumed ocular and central nervous system tuberculosis in a patient with the acquired immunodeficiency syndrome. Am J Ophthalmol. 1996; 121:217-219. [PubMed: 8623897]

57. Perez Blazquez E, Montero Rodriguez M, Mendez Ramos MJ. Tuberculous choroiditis and acquired immunodeficiency syndrome. Ann Ophthalmol. 1994; 26:50-54. [PubMed: 8010705]

58. Morinelli EN, Dugel PU, Riffenburgh R, Rao NA. Infectious multifocal choroiditis in patients with acquired immune deficiency syndrome. Ophthalmology. 1993; 100:1014-1021. [PubMed: 8321524]

59. Dollfus, MA. Fundus lesions in tuberculous meningitis and miliary pulmonary tuberculosis treated with streptomycin (transl.). In: Loutfallah, M.; Clarence, HA., translators. Am J Ophthalmol. Vol. 32. 1949. p. 821-824.

60. Olazábal F Jr. Choroidal tubercles. A neglected sign. JAMA. 1967; 200:374-377. [PubMed: 6071509]

61. Snider DE Jr, Cauthen GM, Farer LS, Kelly GD, Kilburn JO, Good RC, Dooley SW. Drug-resistant tuberculosis. Am Rev Respir Dis. 1991; 144:732. [PubMed: 1909847]

62. Seward DN. Tuberculoma of the ciliary body. Med J Aust. 1973; 1:297-298. [PubMed: 4693221]

63. Ni C, Papale JJ, Robinson NL, Wu BF. Uveal tuberculosis. Int Ophthalmol Clin. 1982; 22:103124.

64. Jabbour NM, Faris B, Trempe CL. A case of pulmonary tuberculosis presenting with a choroidal tuberculoma. Ophthalmology. 1985; 92:834-837. [PubMed: 4034179]

65. Cangemi FE, Friedman AH, Josephberg R. Tuberculoma of the choroid. Ophthalmology. 1980; 87:252-258. [PubMed: 7422265]

66. Lyon CE, Grimson BS, Peiffer RL Jr, Merritt JC. Clinicopathological correlation of a solitary choroidal tuberculoma. Ophthalmology. 1985; 92:845-850. [PubMed: 3897938]

67. Saxena S, Singhal V, Akduman L. Three-dimensional spectral domain optical coherence tomography imaging of the retina in choroidal tuberculoma. BMJ Case Rep. 2013; 2013:2013.

68. Salman A, Parmar P, Rajamohan M, Vanila CG, Thomas PA, Jesudasan CA. Optical coherence tomography in choroidal tuberculosis. Am J Ophthalmol. 2006; 142:170-172. [PubMed: 16815274]

69. Goldberg MF. Presumed tuberculous maculopathy. Retina. 1982; 2:47-50. [PubMed: 7178676]

70. Shah SM, Howard RS, Sarkies NJ, Graham EM. Tuberculosis presenting as retinal vasculitis. J R Soc Med. 1988; 81:232-233. [PubMed: 3373471]

71. Leng T, Schefler AC, Murray TG. Retinal vascular tumor and peripheral retinal vasculitis in the setting of systemic tuberculosis. Ophthalmic Surg Lasers Imaging. 2009; 40:409-412. [PubMed: 19634748]

72. Chung YM, Yeh TS, Sheu SJ, Liu JH. Macular subretinal neovascularization in choroidal tuberculosis. Ann Ophthalmol. 1989; 21:225-229. [PubMed: 2475047]

73. Gur S, Silverstone BZ, Zylberman R, Berson D. Chorioretinitis and extrapulmonary tuberculosis. Ann Ophthalmol. 1987; 19:112-115. [PubMed: 3566033]

74. Mahyudin M, Choo MM, Ramli NM, Omar SS. Ocular tuberculosis initially presenting as central retinal vein occlusion. Case Rep Ophthalmol. 2010; 1:30-35. [PubMed: 21116342]

75. Elliot AJ. Recurrent intraocular hemorrhage in young adults (Eales's disease); a report of thirty-one cases. Trans Am Ophthalmol Soc. 1954-1955; 52:811-875.

76. Biswas J, Therese L, Madhavan HN. Use of polymerase chain reaction in detection of Mycobacterium tuberculosis complex DNA from vitreous sample of Eales' disease. Br J Ophthalmol. 1999; 83:994.

77. Madhavan HN, Therese KL, Gunisha P, Jayanthi U, Biswas J. Polymerase chain reaction for detection of Mycobacterium tuberculosis in epiretinal membrane in Eales' disease. Invest Ophthalmol Vis Sci. 2000; 41:822-825. [PubMed: 10711699]

78. Gupta V, Gupta A, Rao NA. Intraocular tuberculosis—an update. Surv Ophthalmol. 2007; 52:561587. [PubMed: 18029267] 
79. Verma A, Biswas J, Dhanurekha L, Gayathri R, Lily Therese K. Detection of Mycobacterium tuberculosis with nested polymerase chain reaction analysis in enucleated eye ball in Eales' disease. Int Ophthalmol. Oct 24.2015 doi: 10.1007/s10792-015-0144-9

80. Arrell RW. Acute tuberculous panophthalmitis. Arch Ophthalmol. 1967; 78:51-54. [PubMed: 6027735]

81. Demirci H, Shields CL, Shields JA, Eagle RC Jr. Ocular tuberculosis masquerading as ocular tumors. Surv Ophthalmol. 2004; 49:78-89. [PubMed: 14711441]

82. Anders N, Wollensak G. Ocular tuberculosis in systemic lupus erythematosus and immunosuppressive therapy. Klin Monatsbl Augenheilkd. 1995; 207:368-371. In German. [PubMed: 8583748]

83. Khalil M, Lindley S, Matouk E. Tuberculosis of the orbit. Ophthalmology. 1985; 92:1624-1627. [PubMed: 4080333]

84. Pillai S, Malone TJ, Abad JC. Orbital tuberculosis. Ophthal Plast Reconstr Surg. 1995; 11:27-31.

85. Sheridan PH, Edman JB, Starr SE. Tuberculosis presenting as an orbital mass. Pediatrics. 1981; 67:874-875. [PubMed: 6785712]

86. Spoor TC, Harding SA. Orbital tuberculosis. Am J Ophthalmol. 1981; 91:644-647. [PubMed: 6786099]

87. Salam T, Uddin JM, Collin JR, Verity DH, Beaconsfield M, Rose GE. Periocular tuberculous disease: experience from a UK eye hospital. Br J Ophthalmol. 2015; 99:582-585. [PubMed: 25472949]

88. D'Souza P, Garg R, Dhaliwal RS, Jain R, Jain M. Orbital-tuberculosis. Int Ophthalmol. 1994; 18:149-152. [PubMed: 7852020]

89. Maurya OP, Patel R, Thakur V, Singh R. Tuberculoma of the orbit—a case report. Indian J Ophthalmol. 1990; 38:191-192. [PubMed: 2086476]

90. Roberts BN, Lane CM. Orbital tuberculosis. Eye (London). 1997; 11:138-139.

91. van Assen S, Lutterman JA. Tuberculous dacryoadenitis: a rare manifestation of tuberculosis. Neth J Med. 2002; 60:327-329. [PubMed: 12481880]

92. El-Asrar AMA, Abouammoh M, Al-Mezaine HS. Tuberculous uveitis. Middle East Afr J Ophthalmol. 2009; 16:188-201. [PubMed: 20404986]

93. Alvarez S, McCabe WR. Extrapulmonary tuberculosis revisited: a review of experience at Boston City and other hospitals. Medicine (Baltimore). 1984; 63:25-55. [PubMed: 6419006]

94. Abrams J, Schlaegel TF Jr. The tuberculin skin test in the diagnosis of tuberculous uveitis. Am J Ophthalmol. 1983; 96:295-298. [PubMed: 6614107]

95. Sakai J, Matsuzawa S, Usui M, Yano I. New diagnostic approach for ocular tuberculosis by ELISA using the cord factor as antigen. Br J Ophthalmol. 2001; 85:130-133. [PubMed: 11159472]

96. Peneau A, Moinard D, Berard I, Pascal O, Moisan JP. Detection of mycobacteria using the polymerase chain reaction. Eur J Clin Microbiol Infect Dis. 1992; 11:270-271. [PubMed: 1597210]

97. Arora SK, Gupta V, Gupta A, Bambery P, Kapoor GS, Sehgal S. Diagnostic efficacy of polymerase chain reaction in granulomatous uveitis. Tuber Lung Dis. 1999; 79:229-233. [PubMed: 10692991]

98. Biswas J, Kumar SK, Rupauliha P, Misra S, Bharadwaj I, Therese L. Detection of Mycobacterium tuberculosis by nested polymerase chain reaction in a case of subconjunctival tuberculosis. Cornea. 2002; 21:123-125. [PubMed: 11805524]

99. Bowyer JD, Gormley PD, Seth R, Downes RN, Lowe J. Choroidal tuberculosis diagnosed by polymerase chain reaction. A clinicopathologic case report. Ophthalmology. 1999; 106:290-294. [PubMed: 9951479]

100. El-Ghatit AM, El-Deriny SM, Mahmoud AA, Ashi AS. Presumed periorbital lupus vulgaris with ocular extension. Ophthalmology. 1999; 106:1990-1993. [PubMed: 10519597]

101. Sarvananthan N, Wiselka M, Bibby K. Intraocular tuberculosis without detectable systemic infection. Arch Ophthalmol. 1998; 116:1386-1388. [PubMed: 9790648]

102. Salman A, Parmar P, Rajamohan M, Thomas PA, Jesudasan N. Subretinal fluid analysis in the diagnosis of choroidal tuberculosis. Retina. 2003; 23:796-799. [PubMed: 14707830] 
103. Ortega-Larrocea G, Bobadilla-del-Valle M, Ponce-de-León A, Sifuentes-Osornio J. Nested polymerase chain reaction for Mycobacterium tuberculosis DNA detection in aqueous and vitreous of patients with uveitis. Arch Med Res. 2003; 34:116-119. [PubMed: 12700006]

104. Mori T. Usefulness of interferon-gamma release assays for diagnosing TB infection and problems with these assays. J Infect Chemother. 2009; 15:143-155. [PubMed: 19554399]

105. Ang M, Htoon HM, Chee SP. Diagnosis of tuberculous uveitis: clinical application of an interferon-gamma release assay. Ophthalmology. 2009; 116:1391-1396. [PubMed: 19576501]

106. Kratka WH. Isoniazid and ocular tuberculosis; an evaluation of experimental and clinical studies. AMA Arch Ophthalmol. 1955; 54:330-344. [PubMed: 13248293]

107. Leopold IH, Nichols A. Intraocular penetration of streptomycin following systemic and local administration. Arch Ophthal. 1946; 35:33-38.

108. Gardiner PA, Michaelson IC, Rees RJ, Robson JM. Intra-vitreous streptomycin: its toxicity and diffusion. Br J Ophthalmol. 1948; 32:449-456.

109. Outman WR, Levitz RE, Hill DA, Nightingale CH. Intraocular penetration of rifampin in humans. Antimicrob Agents Chemother. 1992; 36:1575-1576. [PubMed: 1510456]

110. Fraundelder, FT. Drug-Induced Ocular Side Effects and Drug Interactions. 3rd. Lea \& Febiger; Philadelphia, PA: 1989.

111. Potter J, Agrawal R, Barraclough C, Rahman F, Westcott M, Pavesio CE, White V. Moxifloxacin: an alternative to ethambutol for the treatment of presumed ocular tuberculosis. Ocul Immunol Inflamm Aug. 2015; 19:1-7.

112. Ruan Q, Liu Q, Sun F, Shao L, Jin J, Yu S, Ai J, Zhang B, Zhang W. Moxifloxacin and gatifloxacin for initial therapy of tuberculosis: a meta-analysis of randomized clinical trials. Emerg Microbes Infect. 2016; 5:e12. [PubMed: 26905025]

113. Balashevich LI. Argon laser coagulation in focal chorioretinitis. Oftalmol Zh. 1984; 1984(7):414416. In Russian.

114. Volkman HE, Pozos TC, Zheng J, Davis JM, Rawls JF, Ramakrishnan L. Tuberculous granuloma induction via interaction of a bacterial secreted protein with host epithelium. Science. 2010; 327:466-469. [PubMed: 20007864]

115. Frueh BE, Dubuis O, Imesch P, Böhnke M, Bodmer T. Mycobacterium szulgai keratitis. Arch Ophthalmol. 2000; 118:1123-1124. [PubMed: 10922211]

116. Rosenbaum PS, Mbekeani JN, Kress Y. Atypical mycobacterial panophthalmitis seen with iris nodules. Arch Ophthalmol. 1998; 116:1524-1527. [PubMed: 9823359]

117. Mason JO. Treatment of large macular choroidal tubercle improves vision. Arch Ophthalmol. 2000; 118:1136-1137. [PubMed: 10922216]

118. Saxena S, Manisha, Meyer CH. Three-dimensional spectral domain optical coherence tomography in X linked foveal retinoschisis. BMJ Case Rep. 2013; 2013 bcr2012007661. 

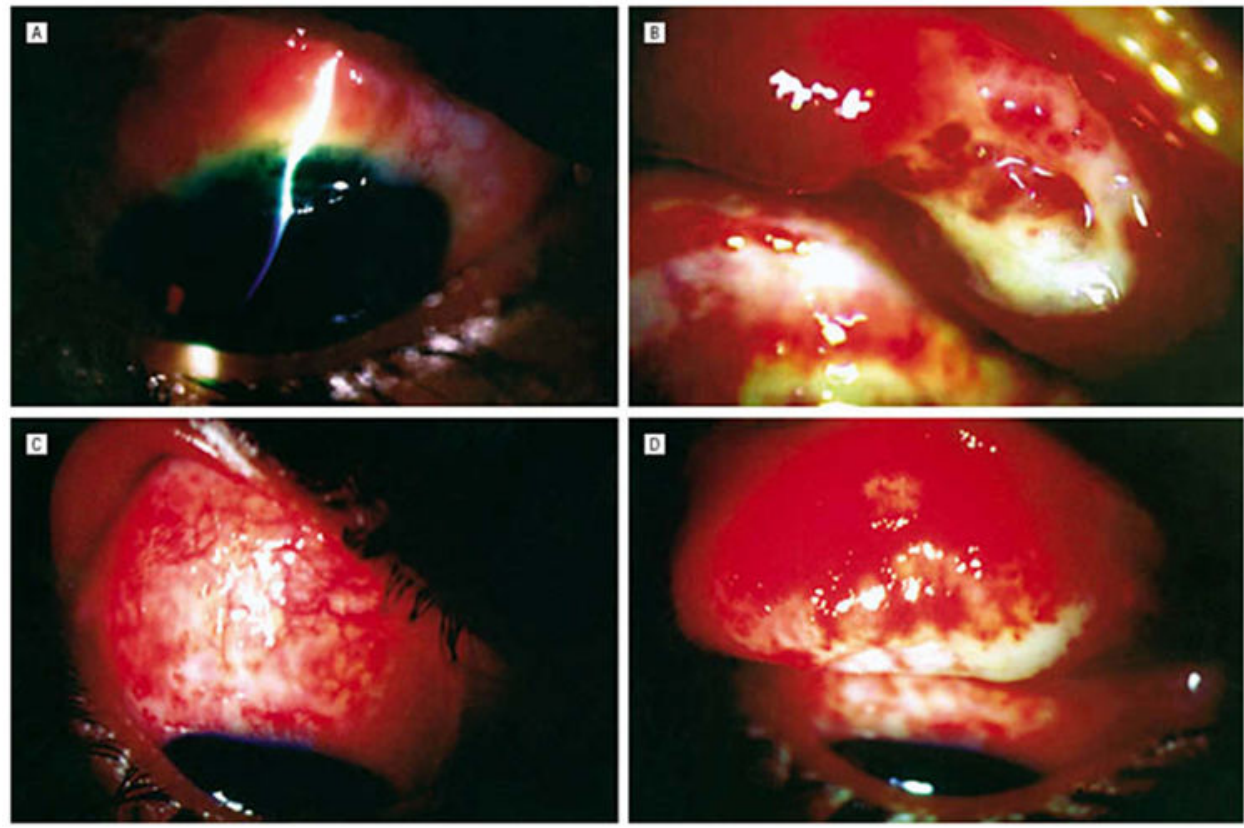

Figure 1.

(A) Case 1. Shown is a bulbar conjunctival mass contiguous with a peripheral corneal ulcer with $80 \%$ stromal thinning. (B) Everted upper eyelid shows diffuse papillary reaction with tarsal necrosis laterally. (C) Case 2. Downgaze shows ulcerated bulbar conjunctiva. (D) Everted upper eyelid shows diffuse velvety appearance, with cheesy white areas of necrosis involving the upper tarsal border. Reprinted with permission from the Archives of Ophthalmology (27). Copyright 2003 American Medical Association. All rights reserved. 


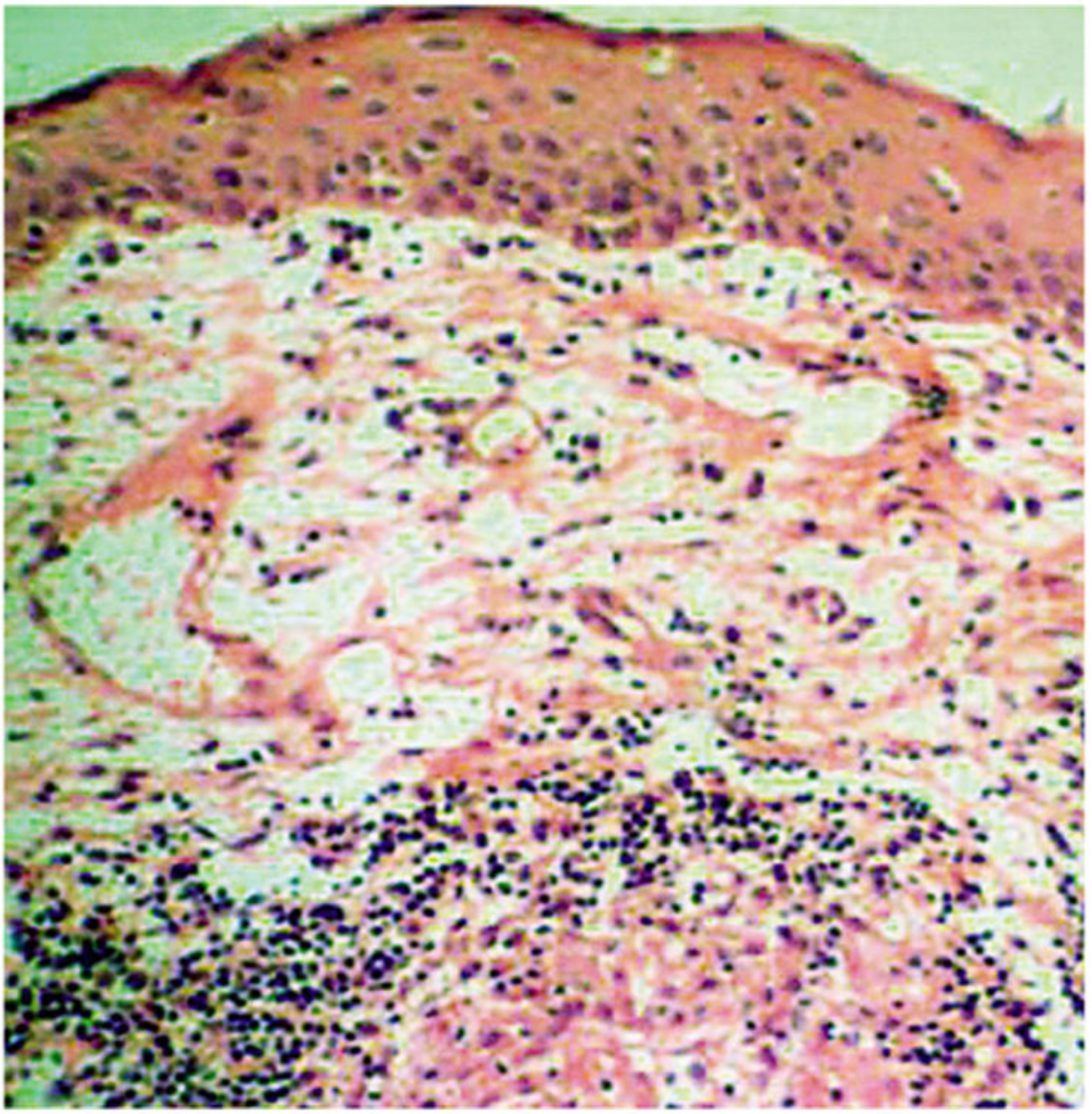

Figure 2.

Case 1. A section from the bulbar conjunctiva shows an intact epithelium with discrete epithelioid cell granuloma in the deeper stroma, rimmed by lymphocytes (hematoxylineosin; original magnification, $\times 250$ ). Reprinted with permission from the Archives of Ophthalmology (27). Copyright 2003 American Medical Association. All rights reserved. 

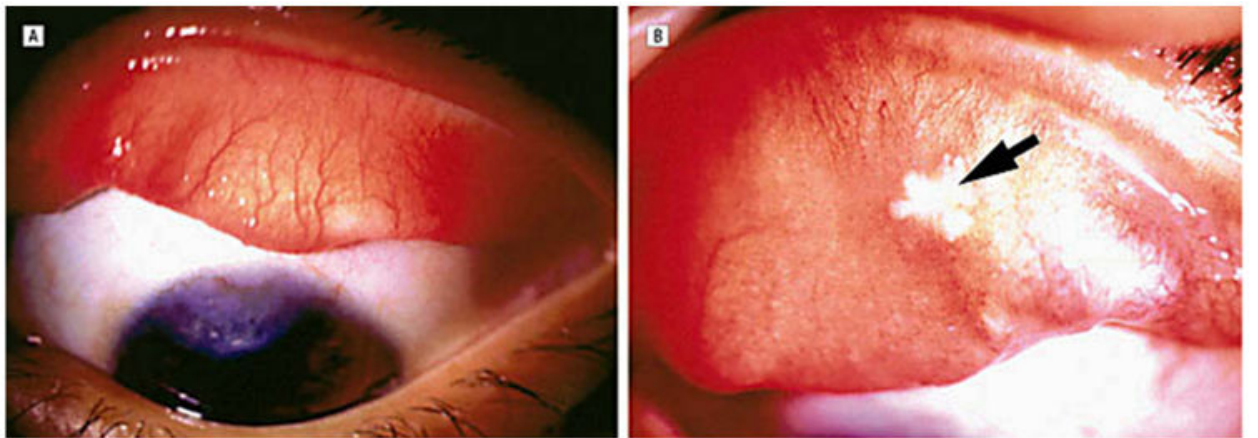

Figure 3.

(A) Case 1. At 1-year follow-up, the left eye shows a superior vascularized corneal scar with normal-appearing bulbar and tarsal conjunctiva. (B) Case 2. At 3-month follow-up, the everted right upper eyelid shows a residual area of necrosis (arrow) with mild persistent papillary reaction. Reprinted with permission from the Archives of Ophthalmology (27). Copyright 2003 American Medical Association. All rights reserved. 


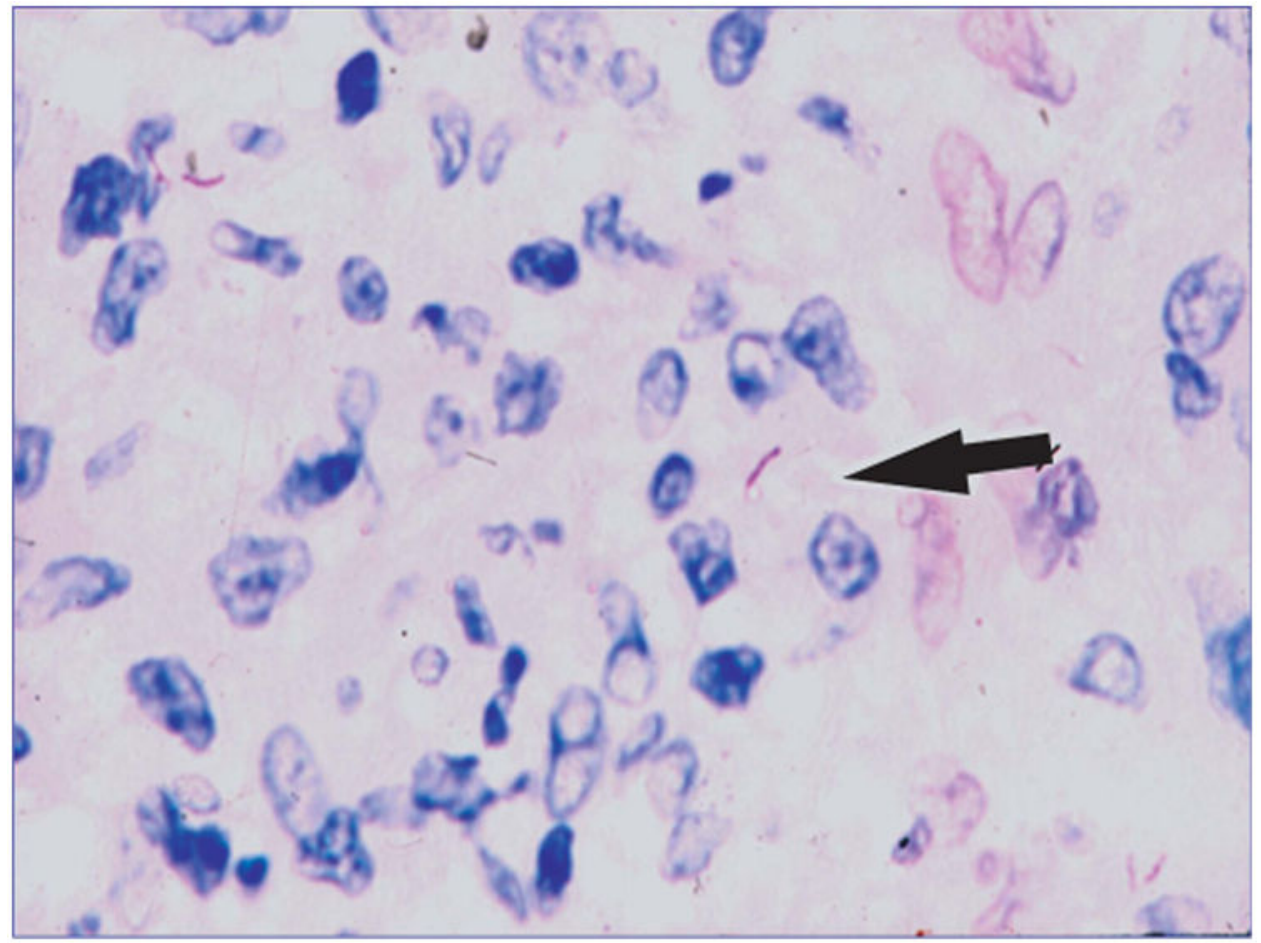

Figure 4.

Acid-fast stain of a conjunctival biopsy specimen shows acid-fast positive rods (arrow) within epithelioid histiocytes. 


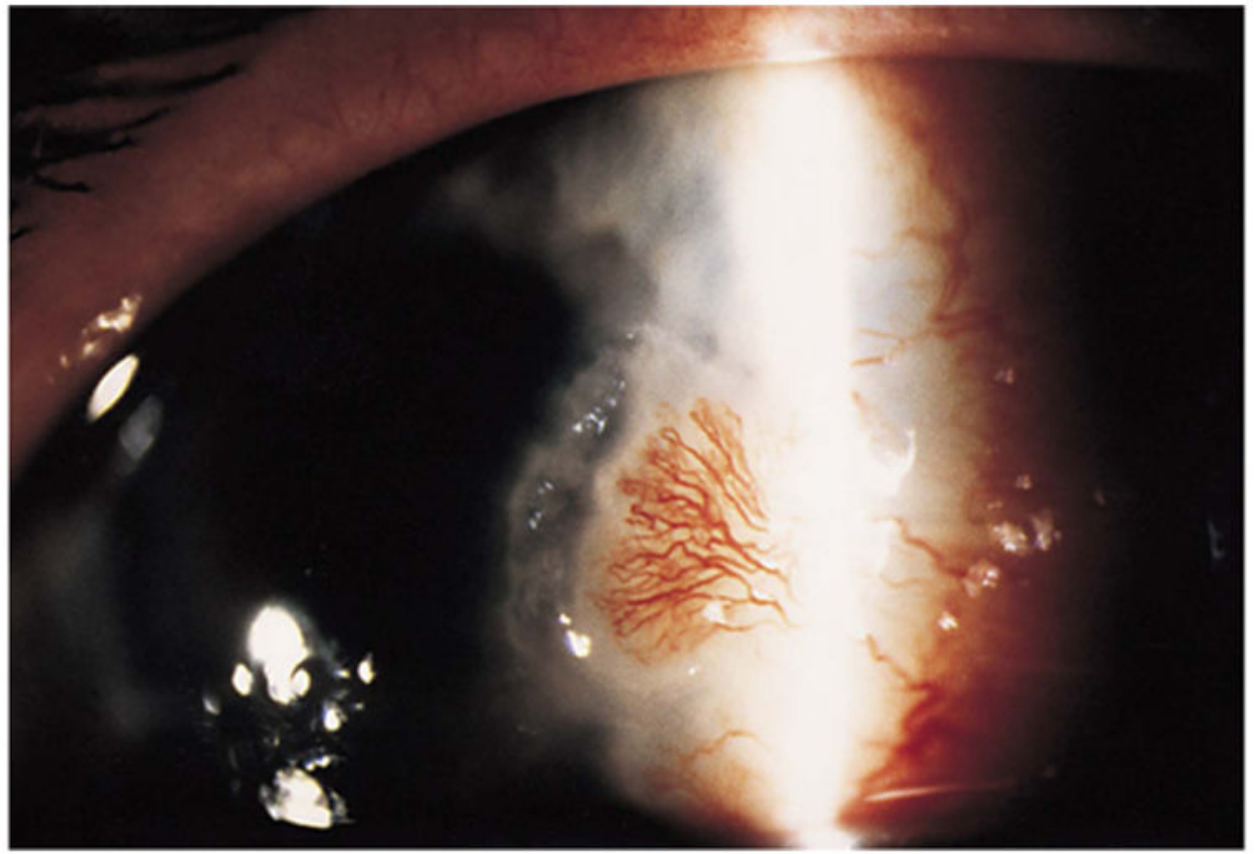

Figure 5.

Slit lamp picture of the left cornea showing a peripheral corneal ulcer and a heavily vascularized nodule. Reprinted with permission from the Archives of Ophthalmology (115). Copyright 2000 American Medical Association. All rights reserved. 


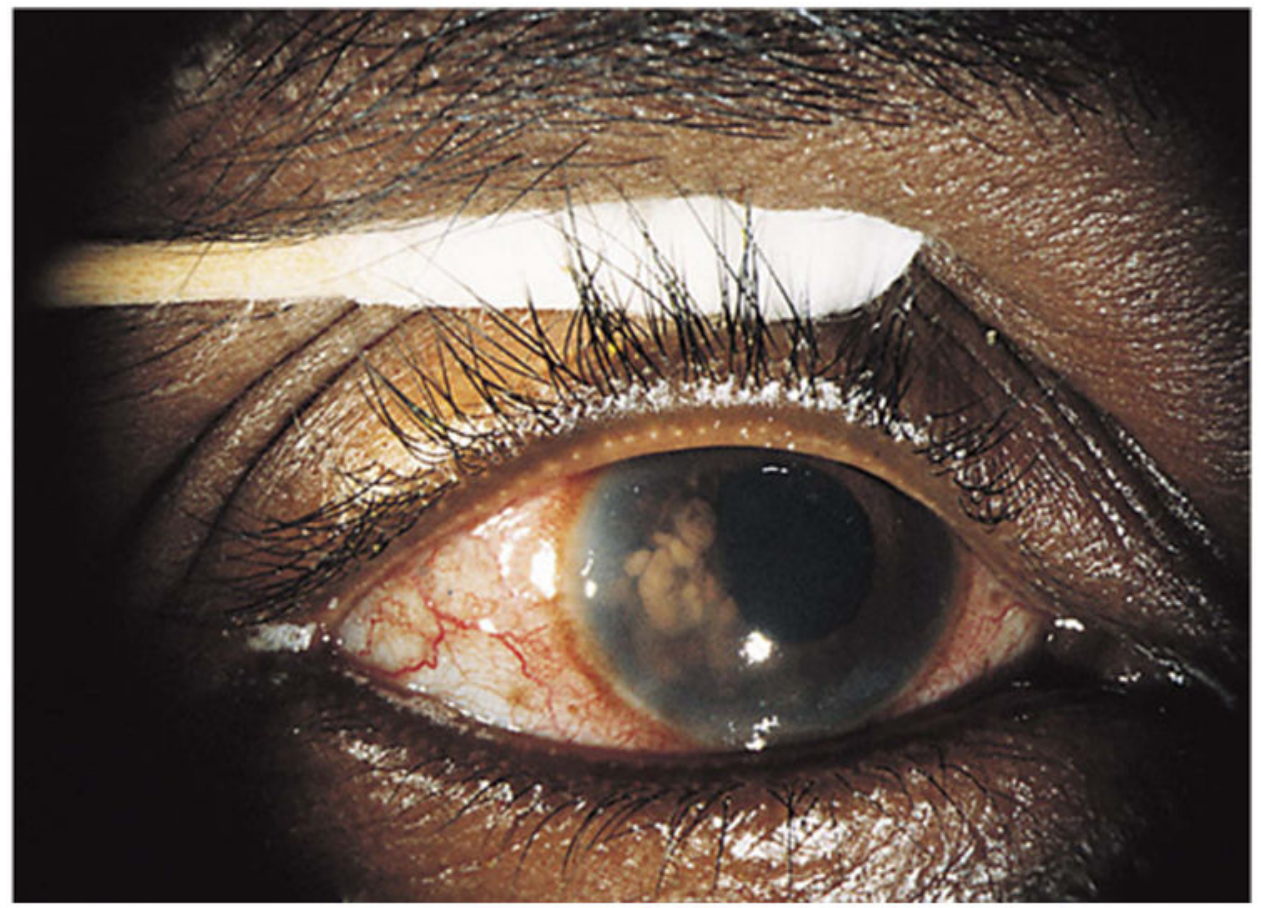

Figure 6.

Clinical appearance of a right eye shows mild conjunctival vasodilation and numerous confluent, temporal, tan iris nodules. Reprinted with permission from the Archives of Ophthalmology (116). Copyright 1998 American Medical Association. All rights reserved. 

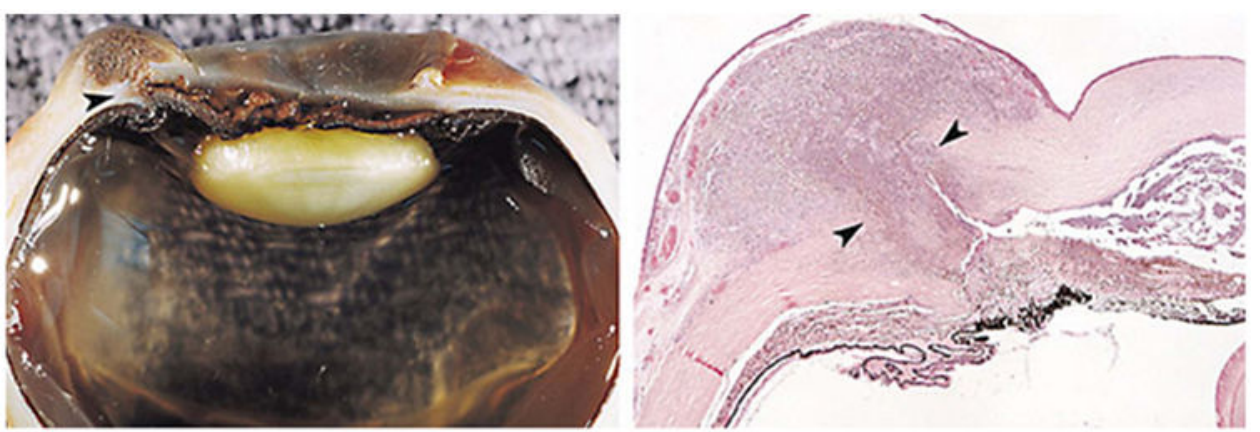

Figure 7.

(Left) Gross appearance of the enucleated right eye. Note the scleral necrosis and the perilimbal scleral rupture (arrowhead) located interiorly. The limbal conjunctiva covers a dome-shaped, brown mass. (Right) Histopathological appearance of the enucleated right eye with a subconjunctival necrotic and inflammatory mass. There is necrosis of the iris, and the anterior chamber contains necrotic debris (arrowheads) (hematoxylineosin; original magnification, $\times 5$ ). Reprinted with permission from the Archives of Ophthalmology (116). Copyright 1998 American Medical Association. All rights reserved. 

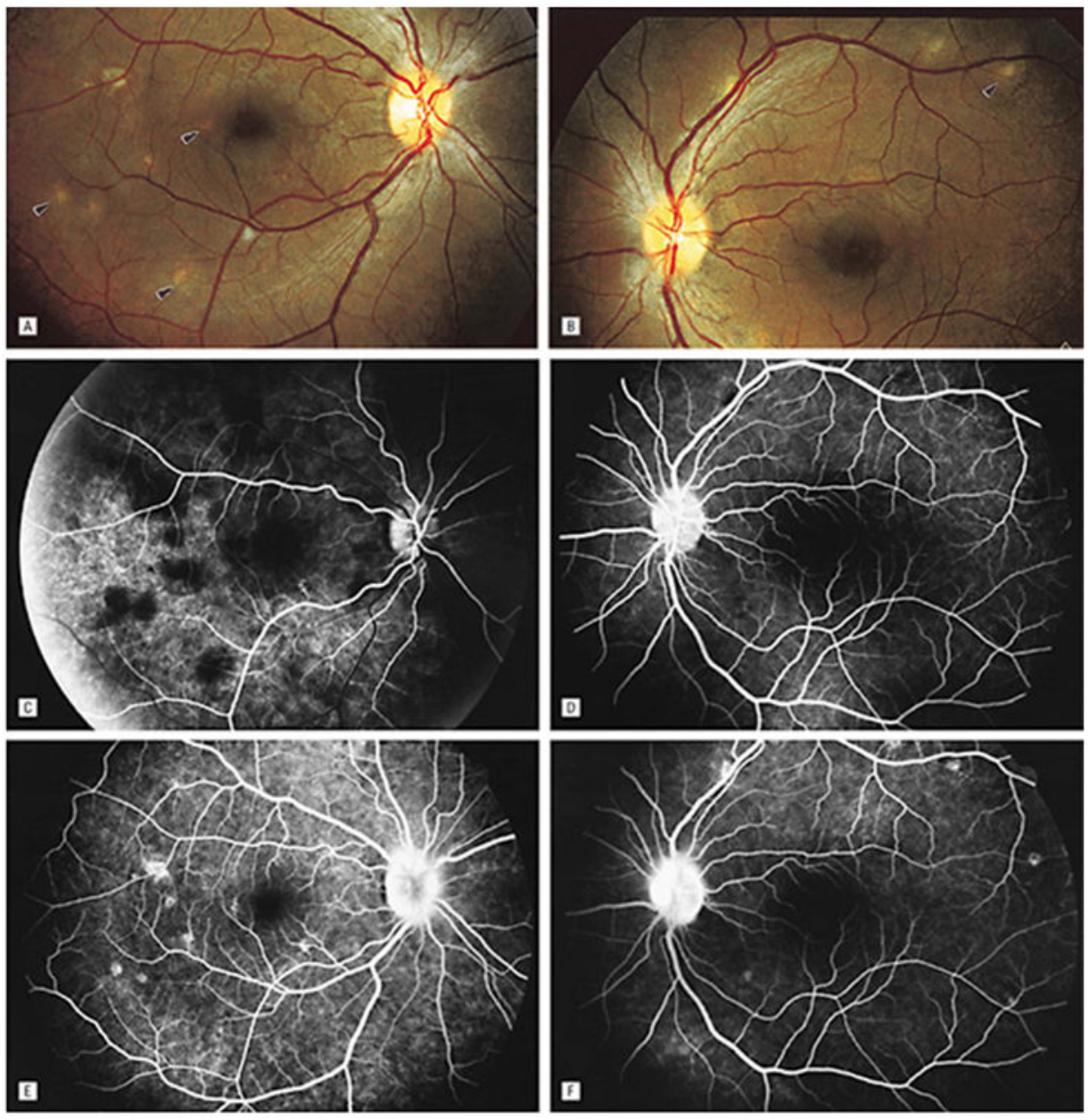

Figure 8.

Fundus photographs of the right (A) and left (B) eyes show bilateral, multifocal choroiditis (arrowheads). Serial FA photographs (C to F) show early blocking hypofluorescence and late-staining hyperfluorescence corresponding to areas of choroidal infiltrate, as well as mild, late leakage from the optic nerve heads in each eye. Reprinted with permission from the Archives of Ophthalmology (53). Copyright 1998 American Medical Association. All rights reserved. 


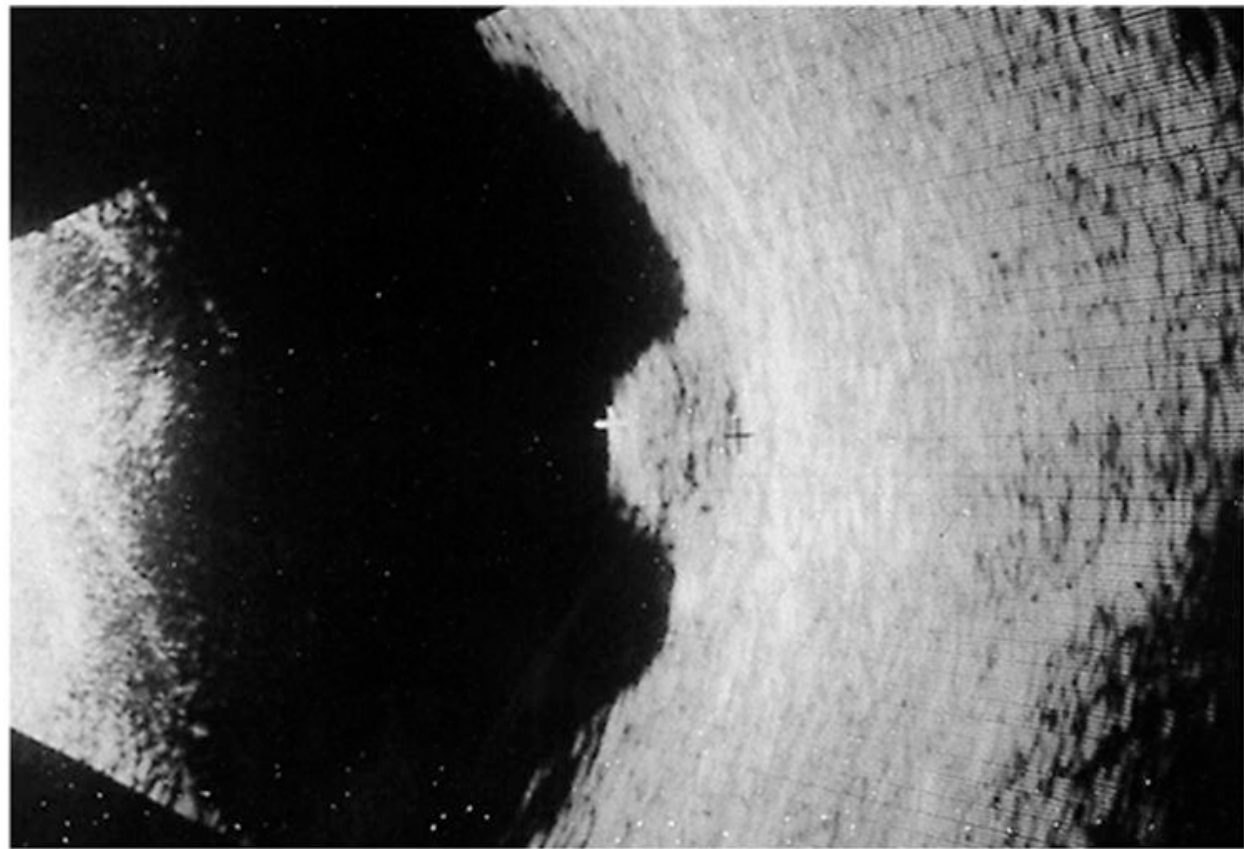

Figure 9.

B-scan ultrasonogram of the left eye showing an acoustically dense choroidal lesion with no choroidal excavation. Reprinted with permission from the Archives of Ophthalmology (117). Copyright 2000 American Medical Association. All rights reserved. 

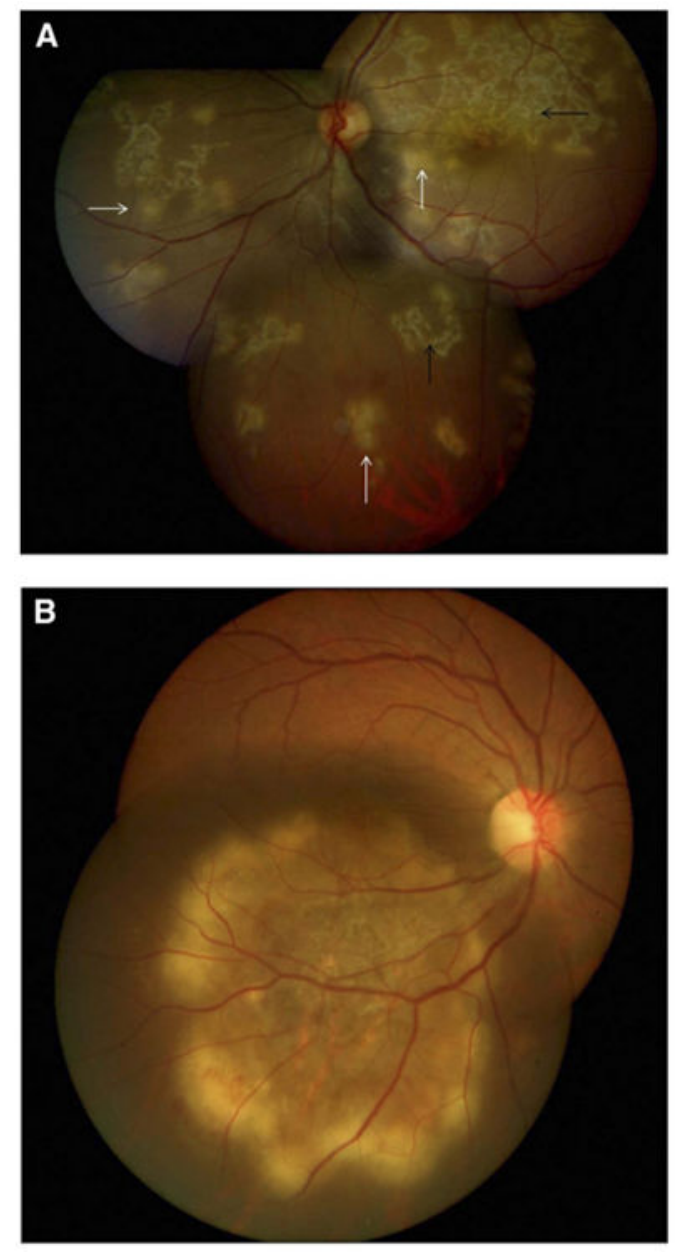

Figure 10.

(A) Left eye fundus photograph showing discrete, multifocal active lesions (white arrows) of serpiginous-like choroiditis becoming confluent, along with old healing lesions (black arrows) that are noncontiguous to the optic disc and involve the posterior pole and peripheral fundus. (B) Right eye fundus photograph showing a solitary, placoid lesion of serpiginouslike choroiditis having an active edge with amoeboid spread and a healing center. Reprinted with permission from the American Academy of Ophthalmology (55). Copyright 2012 Elsevier. All rights reserved. 

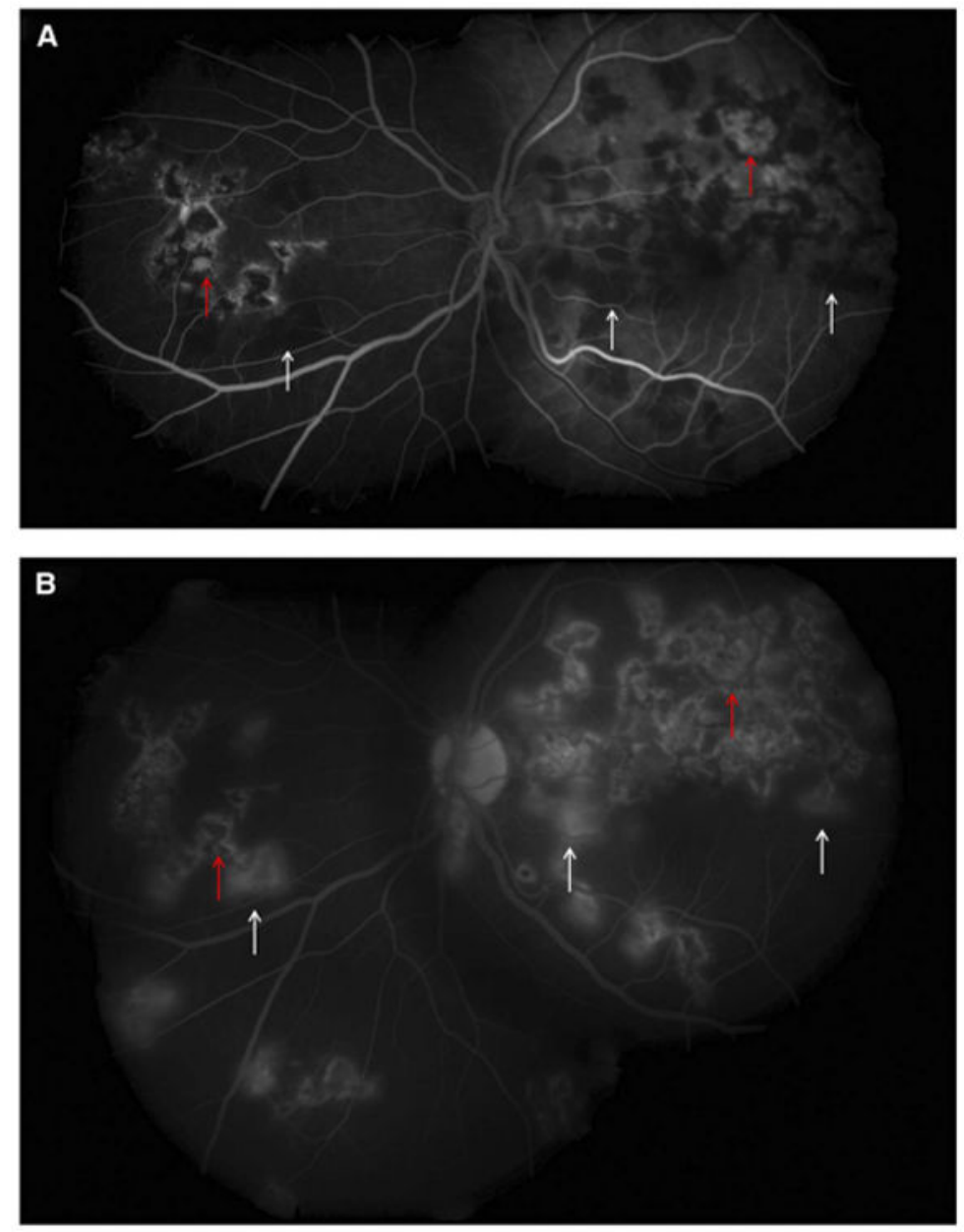

Figure 11.

(A) Fundus fluorescein angiography of the same eye as in Fig. 10 showing active lesions (white arrows) that are hypofluorescent in the early phase. The inactive scars show transmission hyperfluorescence (red arrows). (B) Fundus FA of the same eye as in Fig. 10 showing hyperfluorescence of active lesions in the late phase (white arrows). The inactive scars show transmission hyperfluorescence (red arrows). Reprinted with permission from the American Academy of Ophthalmology (55). Copyright 2012 Elsevier. All rights reserved. 


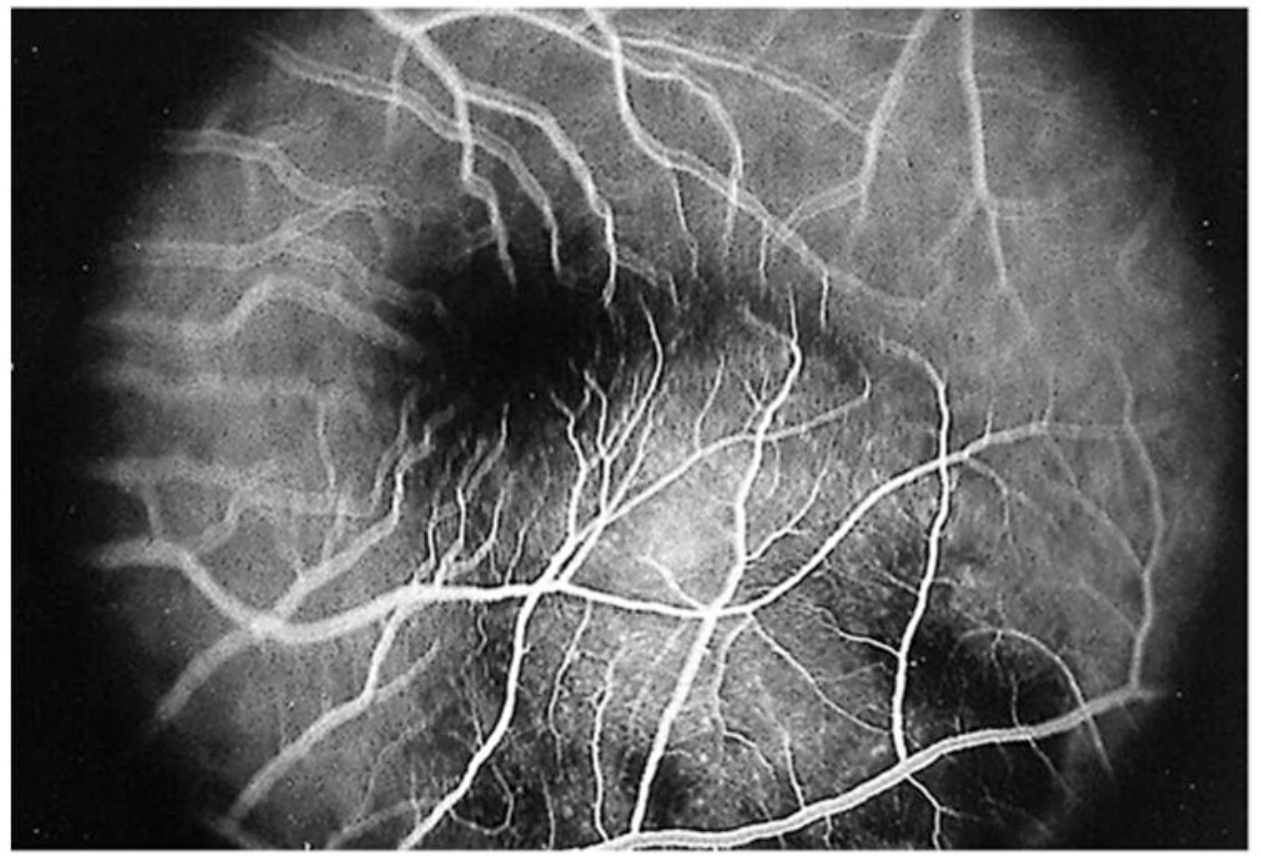

Figure 12.

Fluorescein angiogram in the early venous phase showing early blockage at the edges of the lesion and early hyperfluorescence within the central aspect of the choroidal lesion; the overlying retinal vessels are normal and in focus. The other retinal vessels are not in focus secondary to the thickness of the lesion. Reprinted with permission from the Archives of Ophthalmology (117). Copyright 2000 American Medical Association. All rights reserved. 


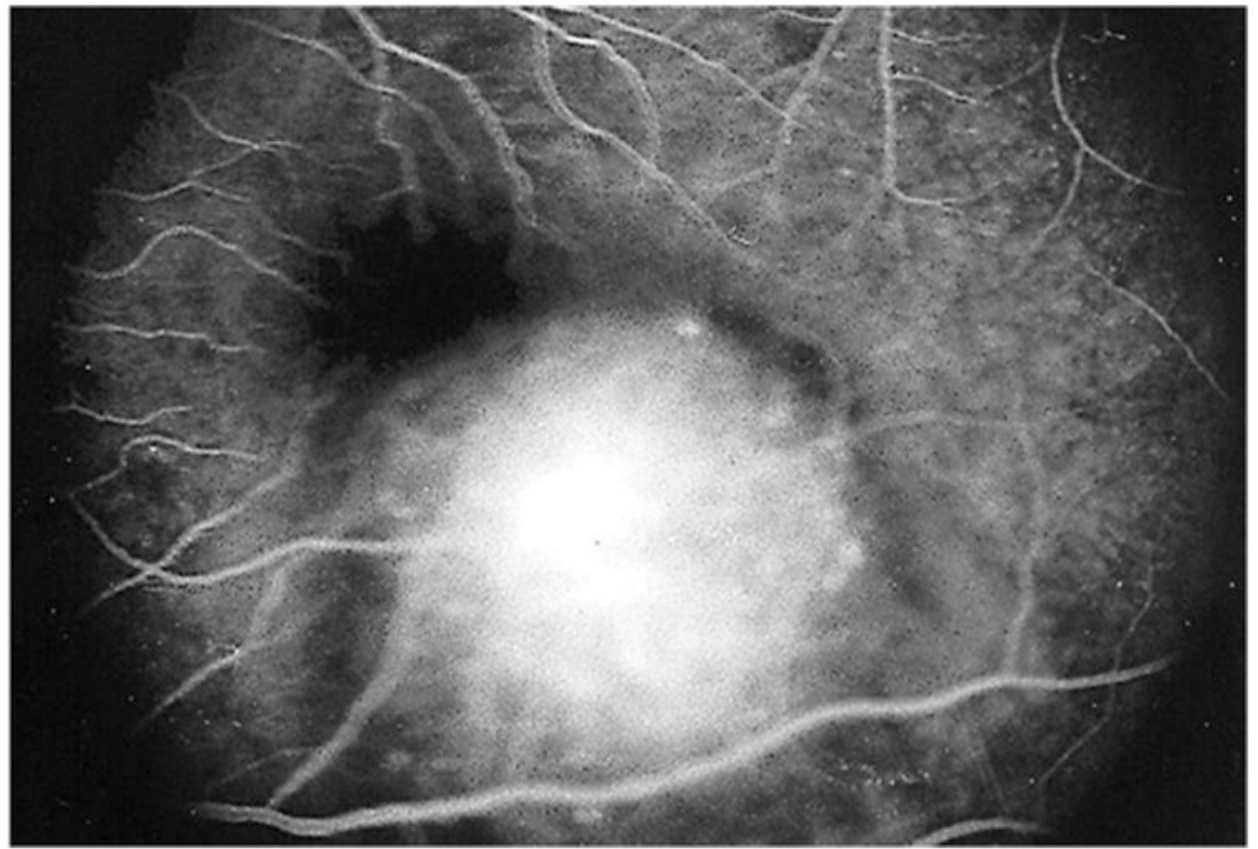

Figure 13.

Fluorescein angiogram in the late phase revealing late staining of the choroidal lesion. Reprinted with permission from the Archives of Ophthalmology (117). Copyright 2000 American Medical Association. All rights reserved. 

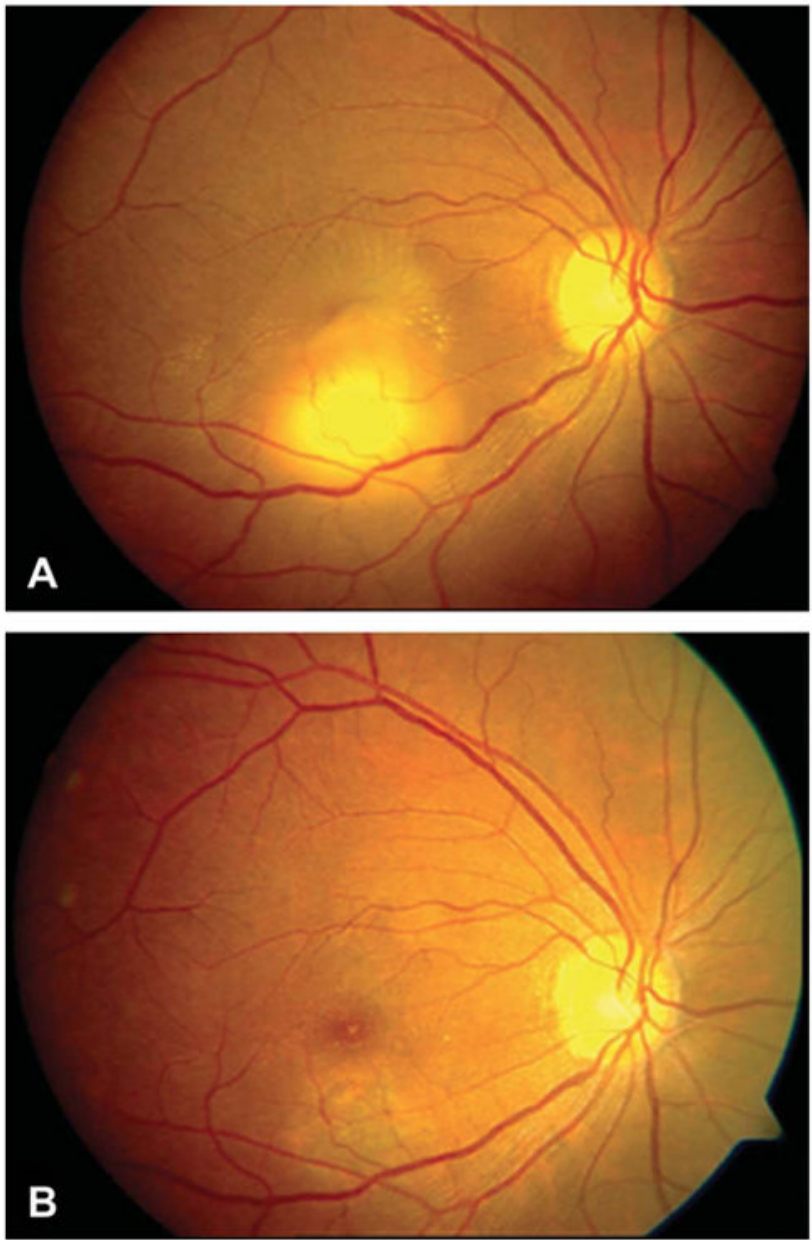

Figure 14.

(A) Fundus photograph of right eye at presentation, showing a tuberculoma at the inferior macula with astrallike exudates. (B) Fundus photograph of the right eye at 9-month followup showing the tuberculoma totally disappeared. Reprinted with permission from Retina (42). Copyright 2012 Wolters Kluwer. All rights reserved. 

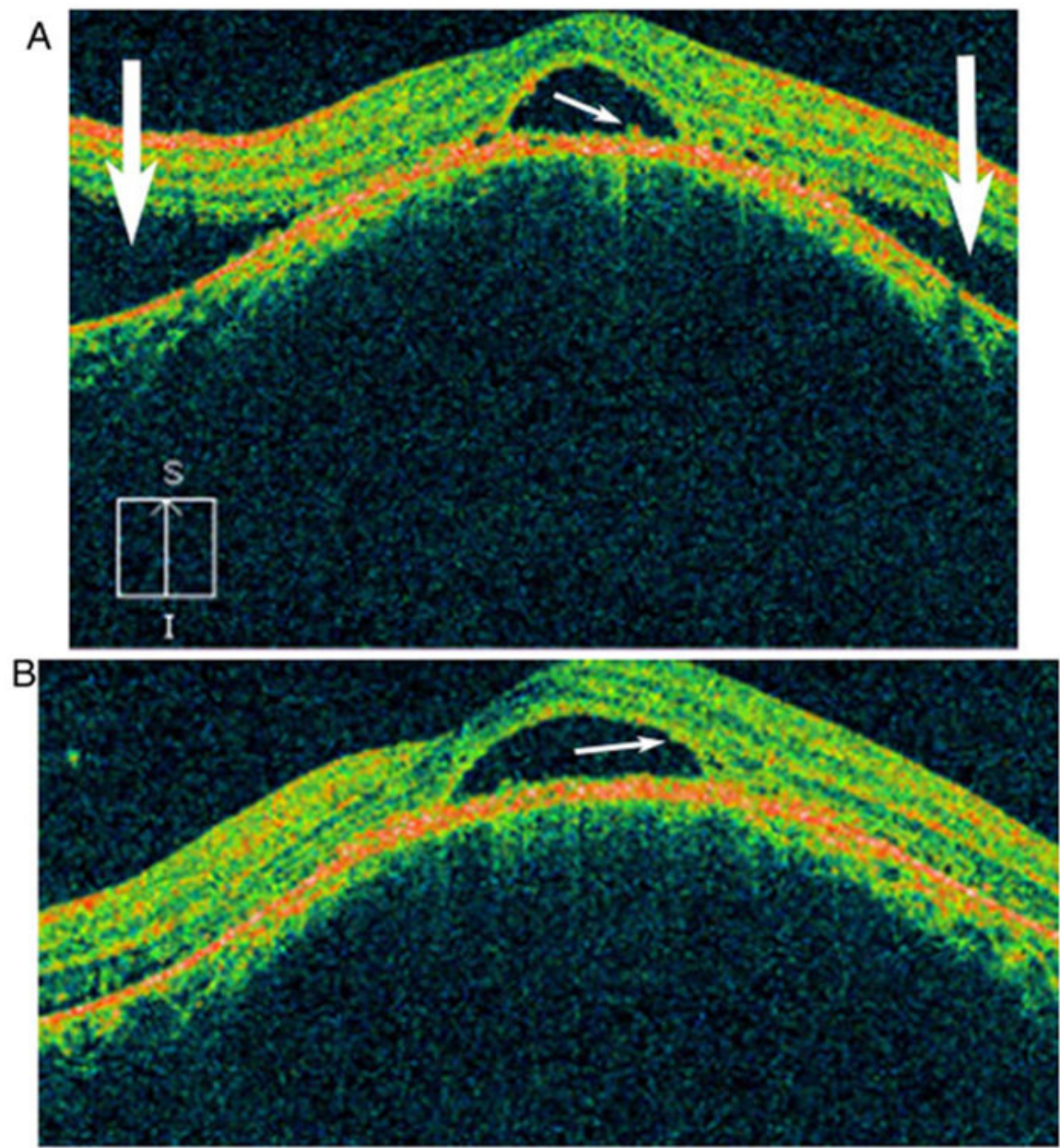

Figure 15.

Spectral domain optical coherence tomography image of the left eye prior to initiation of therapy shows subfoveal neurosensory detachment and proliferating retinal pigment epithelial cells (small white arrow) with serous retinal detachment superiorly and inferiorly (large white arrows) (A) and phagocytosed outer photoreceptor layer cells (small white arrow) (B). Reprinted with permission from the BMJ Case Reports. (118). Copyright 2013 BMJ Publishing Inc. All rights reserved. 


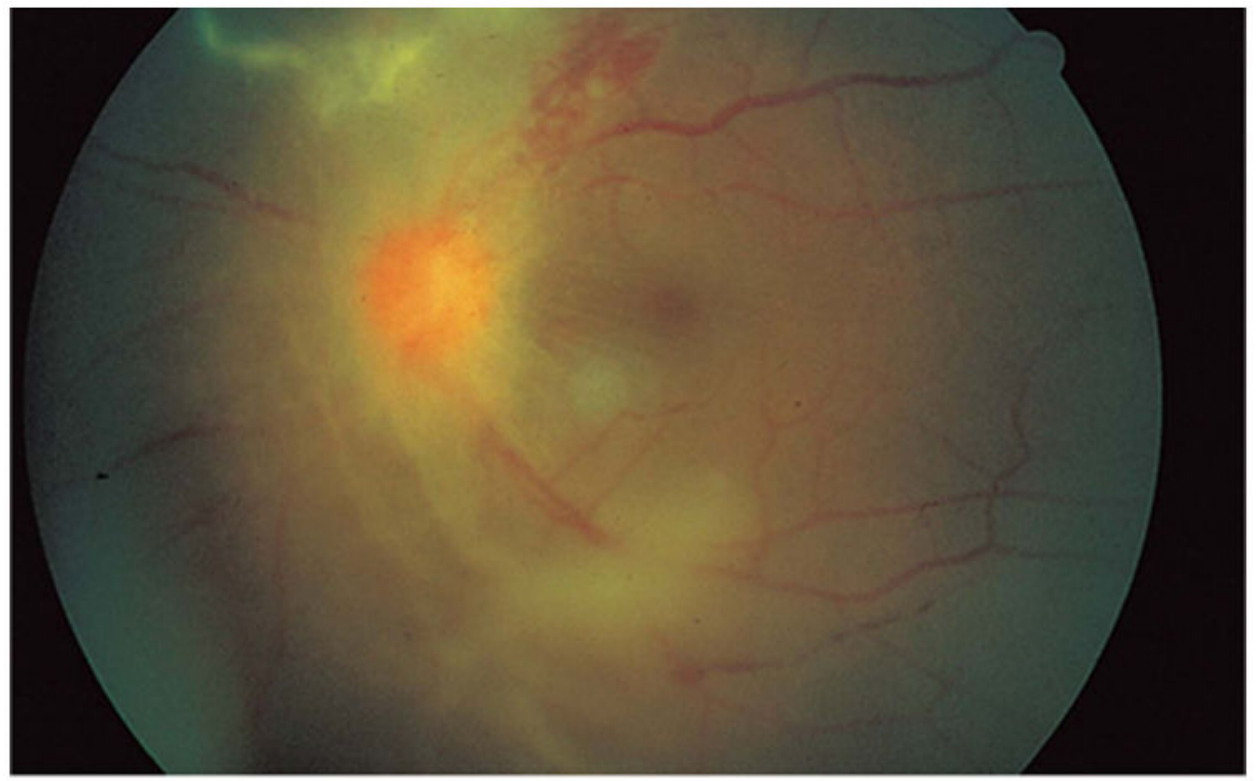

Figure 16.

Retinitis and retinal neovascularization obscuring a clear view of the optic disc in a fundus photograph. Reprinted with permission from the Archives of Ophthalmology (101).

Copyright 1998 American Medical Association. All rights reserved. 


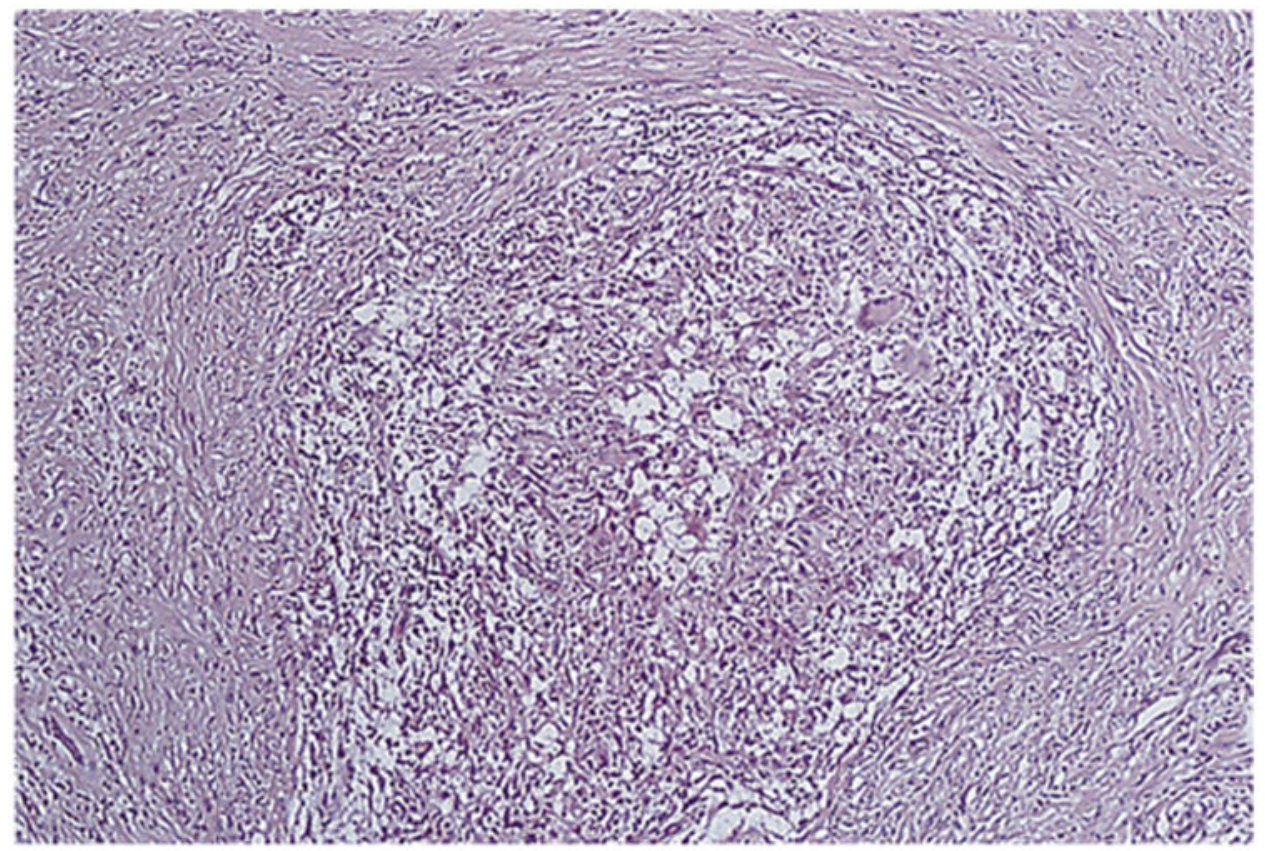

Figure 17.

Noncaseating granuloma from a transvitreal biopsy specimen. Reprinted with permission from the Archives of Ophthalmology (101). Copyright 1998 American Medical Association. All rights reserved. 


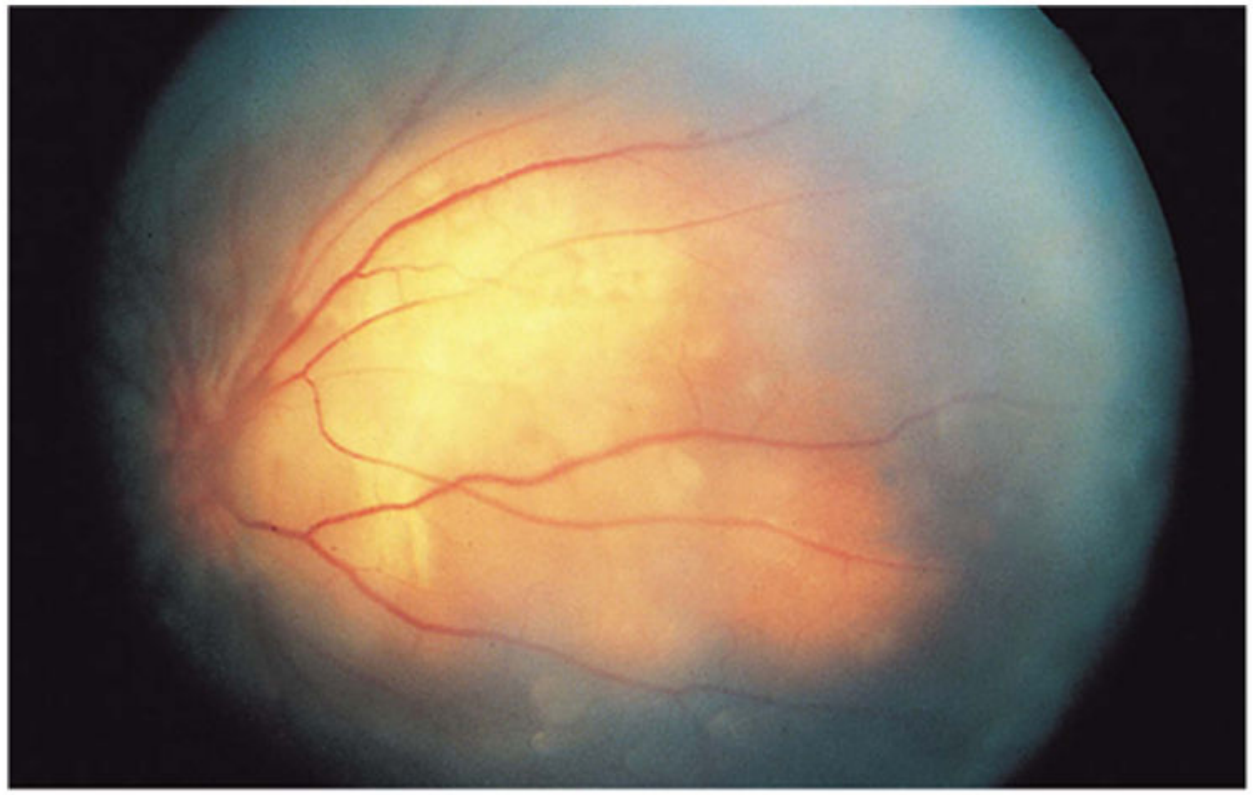

Figure 18.

Left fundus photograph illustrating optic disc new vessels with choroidal mass nasally. Reprinted with permission from the Archives of Ophthalmology (101). Copyright 1998 American Medical Association. All rights reserved. 